NBER Working Paper Series

\author{
SALVORS, FINDERS, GOOD SAMARITANS, AND OTHER \\ RESCUERS: AN ECONOMIC STUDY OF LAW AND ALTRUISM \\ William M. Landes and Richard A. Posner
}

Working Paper No. $\underline{227}$

CENTER FOR ECONOMIC ANALYSIS OF HUMAN BEHAVIOR AND SOCIAL INSTITUTIONS

National Bureau of Economic Research, Inc. 204 Junipero Serra Boulevard, Stanford, CA 94305

January 1978

Preliminary; not for quotation.

NBER working papers are distributed informally and in limited number for comments only. They should not be quoted without written permission of the author.

This report has not undergone the review accorded officlal NBER publications; in particular, it has not yet been submitted for approval by the Board of Directors.

This study was supported in part by a grant to the NBER from the National Science Foundation. 
SALVORS, FINDERS, GOOD SAMARITANS, AND OTHER RESCUERS: AN ECONOMIC STUDY OF LAW AND ALTRUISM

\begin{abstract}
This paper uses economic analysis to illuminate a variety of legal rules relating to rescue, a term we use broadly to describe any attempt to save a person or property from some peril. We first develop a model of a competitive market in rescues, as a benchmark for judging whether the legal rules of rescue can be viewed as attempts to simulate the operation of a competitive market in rescues. The model explicitly incorporates the possibility of rescues motivated by altruism. We then apply the model to a variety of legal settings in which rescue questions arise. We show that the well-developed body of rules governing rescue at sea (including the principles governing salvage awards and the rule of general average) are consistent with the economic model of professional (nonaltruistic) rescue and appropriate in the maritime setting. The rules of the common law governing rescues on land (e.g., the physician who treats a passerby in distress) are also examined, and found to be in the main consistent with our economic model when altruism is taken into account, as are the differences between the maritime and common law rules. We then examine the choice between compensation and liability as methods of inducing rescue, and show that the common law's decision not to impose liability for failure to rescue (the "Good Samaritan" rule) may be consistent with efficiency because of the "tax" effects of such liability. We concluded that the array of legal rules and doctrines examined provide support for the hypothesis that the common law (including traditional maritime law) has been heavily influenced by a concern with achieving efficient allocation of resources.
\end{abstract}


SALVORS, FINDERS, GOOD SAMARITANS, AND OTHER RESCUERS:

AN ECONOMIC STUDY OF LAW AND ALTRUISM*

William M. Landes** and Richard A. Posner ***

INTRODUCTION

The subject of this paper is "rescue," a term we use broadly to cover all attempts to save a person or his property. Some examples will illustrate the variety of legal settings in which a rescue question may arise:

1. A physician finds a person lying unconscious in the street. He renders medical assistance but the person dies. Can the physician charge the estate the cost of the medical services rendered?

2. The master of a ship, in order to prevent it from sinking in a storm, Jettisons some of the cargo. Is the owner of the Jettisoned cargo entitled to any reimbursement for his loss by the owners of the cargo that was saved? If another ship tows the sinking ship to safety,

\footnotetext{
* This study was supported by a grant to the National Bureau of Economic Research from the National Science Foundation for research in law and economics, and by the law and economics program of the University of Chicago Law School. It is not, however, an official National Bureau study because it has not been subjected to the full critical review accorded National Bureau publications, including approval by the Bureau's board of directors. The comments of Peter A. Diamond, Gareth Jones, Alvin K. Klevorick, and participants in workshops at the University of Chicago, U.C.L.A., and the Yale Law School on an earlier draft are gratefully acknowledged, as is the helpful research assistance of Joseph Schiffhouer, Robert Sherwin, and Carl Witschy.
}

* Professor of Economics, University of Chicago Law School; Senior Research Staff, National Bureau of Economic Research.

*** Professor of Law, University of Chicago Law School; Senior Research Staff, National Bureau of Economic Research. 
are its owners or crew entitled to a reward for their efforts from the owners of the ship and/or the owners of the cargo that was saved?

3. A drowning man cries for help, a strong swimmer ignores his cries, and the man drowns. Is the decedent's estate entitled to damages from the swimmer?

4. Suppose the strong swimmer does go to the aid of the drowning person and both drown in the rescue attempt. If the person he tried to save was negligent in getting into trouble in the first place, can the estate of the rescuer obtain damages from the estate of the person he tried to save?

5. Suppose the rescue is attempted and is successful. Subsequently, the rescued person promises to reward the rescuer, but reneges. Is the promise legally enforceable?

6. A man loses his wallet and posts a reward. Someone finds the wallet, returns it, and claims the reward, but the owner refuses to pay, citing a statute that makes it a criminal offense not to return lost property to its owner. Has the finder a cause of action against the owner?

7. A person ties up his boat at another's dock to escape a storm. Can the owner of the dock eject him and his boat as trespassers?

Example $l$ is in the domain of the law of restitution, example 2 of admiralty law, and examples 3 and 4 of tort law. Example 5 involves the contract doctrine known as "moral consideration:" Example 6 raises questions under property and contract law and example 7 under tort and property law. ${ }^{1}$ Questions arising in different fields of law (e.g., torts,

1. Similar questions also arise under the criminal law. For example, is it a crime to kill and eat the weakest passenger in the lifeboat in order to save the others? 
admiralty, restitution) are rarely discussed together. And even within a single field, the tendency to compartmentalization that is endemic to legal scholarship has led to placing rescue questions in different compartments with tight bulkheads between them. ${ }^{2}$ As a result, the variety of legal responses to the problem of rescue, as we have defined the term, have never (to our knowledge) been discussed in one place as different aspects of a single problem. ${ }^{3}$

The scattered legal literature on rescue employs a colorful and suggestive, but also value-laden and obscure, vocabulary dominated by terms like "officious," "volunteer," "unjust enrichment," "implied contract," and "Good Samaritan." The efforts of conventional legal scholarship to give these terms concrete meaning have not been very successful, 4 and there is a growing tendency to acknowledge that, as currently employed, such terms state conclusions rather than guide analysis. 5

2. For example, the "Good Samaritan" problem (example 3) is typically discussed under the rubric of "duty" and the problem of the trespass that is necessary to avert a greater loss (example 7) under the rubric of "incomplete privilege." Both are tort doctrines.

3. The limited efforts that have been made to cross doctrinal boundary lines have not been notably successful. Richard A. Epstein, A Theory of strict Liability, 2 J. Leg. Studies 151, 202-03 (1973), on successive pages expresses (1) his strenuous opposition to the imposition of liability for failure to rescue, on the ground (among others) that it would put the courts in the impossible position of having to write a contract between parties who never agreed on terms, and (2) his apparent willingness to give the rescuer a legal claim to a reward from the person rescued. However, to force the rescued person to compensate the rescuer for unbargained assistance is also to write a contract between parties who never agreed on terms, contrary to Epstein's statement: "It is for good reason that the courts have always refused to make contracts for the parties." Id. at 202.

4. See, for example, Edward W. Hope, Officiousness, 15 Cornell L.Q. 25 (1929), 205 (1930); Restatement of the Law of Restitution, Quasi-Contracts and Constructive Trusts 12 , comment a (American Law Institute 1937) (hereinafter Restatement of Restitution).

5. Cf. Robert Goff \& Gareth Jones, The Law of Restitution 12-13 (1966); Restatement of Restitution $\mathrm{Sl}_{1}$, comment $\mathrm{c}$. 
It is therefore not surprising that specific doctrines and case outcomes are often regarded as being mutually inconsistent, or responsive to some profound but unanalyzable intuition of justice or equity, or determined by national character, ${ }^{6}$ or ideologically motivated--whether by "seafaring communism" $^{7}$ or by libertarianism. 8

Economics can contribute to the understanding of rescue law by demonstrating the intellectual unity of the rescue problem, by clarifying legal analysis of rescue through imparting meaning to important but nebulous legal concepts such as "officiousness" and "unjust enrichment," and by showing that the major doctrines and case outcomes related to rescue have been shaped by a concern with promoting economic efficiency.

Part I of this paper develops an economic model of rescue. ${ }^{9}$ Although our primary interest is in rescues that are not explicitly bargained for or, if bargained for, that arise in situations of bilateral monopoly, we begin

6. Edward W. Hope, supra note 4 , at 29.

7. See J. F. Donaldson et al., The Law of General Average 3 (1964). 8. See, for example, Richard A. Epstein, supra note 3.

9. There have been only limited previous efforts to analyze rescue law in economic terms. See Peter A. Diamond \& James Mirrlees, On the Assignment of Liability: The Uniform Case, 6 Bell J. Econ. \& Management Sci. 487, 512-13 (1975); William M. Landes \& Richard A. Posner, The Private Enforcement of Law, $4 \mathrm{~J}$. Leg. Studies 1, 44-46 (1975); Richard A. Posner, Economic Analysis of Law 76-77 (1973). Posner's second edition draws on an earlier draft of this paper. See Richard A. Posner, Economic Analysis of Law 97-98, 131-34, 188-89 (2d ed. 1977). 
with a model of a competitive market in rescues. This model is then used as a benchmark for evaluating the legal rules governing unbargained or noncompetitive rescues. Part II of the paper applies the model in Part I to a variety of specific legal problems, such as those suggested by the examples with which we began. The principal doctrines discussed are the admiralty doctrines of general average, salvage, and abandonment; the principles of the law of restitution governing the conferral of benefits in cases of emergency or incapacity; common law and statutory regulation of finders of lost or mislaid property; the Good Samaritan (no-duty) doctrine in tort law and its exceptions; and the limitations that Good Samaritan statutes and the tort doctrine of incomplete privilege place on the legal liability of rescuers.

\section{THE ECONOMICS OF RESCUE}

\section{A. The Economics of Professional Rescue}

Professional rescue is our term for the sale (whether voluntarily or through operation of law) of rescue services by profit-maximinzing firms to victims of hazards. We assume that these services are contracted for only in the event that a hazard occurs and that payment for them is contigent on a successful rescue, as in the case of salvage awards to rescuers at sea. 10

1. The Victim. Suppose the victim is a firm (or individual) engaged in hazardous activity, such as shipping cargo by sea, and is subject to a loss of $L_{0}$ if the hazard occurs and rescue fails. Let the probability that the hazard will occur be $\mathrm{p}^{\mathrm{h}}$, and the conditional probability of rescue (conditional on the hazard's occurring) $\mathrm{p}^{\mathrm{r}}$; if the rescue is successful

10. A later section of the paper discusses the choice between contingent payments and fees that are independent of the outcome. 
the firm avoids $\mathrm{L}_{\mathrm{o}}$. The probabilities, in turn, are assumed to be continuously differentiable functions of safety and rescue inputs, respectively, as in

$$
\begin{aligned}
& p^{h}=p^{h}(x) \\
& p^{r}=p^{r}(y)
\end{aligned}
$$

where $x$ denotes the victim's inputs on safety that reduce the probability of the hazard $\left(p_{x}^{h}<0\right.$ and $\left.p_{x x}^{h}>0\right)$ and $y$ the resource inputs (or services) of the professional rescuer that increase the probability of rescue $\left(p_{y}^{r}>0\right.$ and $\left.p_{y y}^{r}<0\right)$. Thus the marginal products of safety and rescue inputs are positive and diminishing.

The expected utility of the victim can be written as

$\bar{U}=\left(I-p^{h}\right) U\left(W_{0}-E(x)\right)+p^{h}\left(I-p^{r}\right) U\left(W_{O}-L_{O}-E(x)\right)+p^{h} p^{r} U\left(W_{O}-E(x)-v y\right)$

where $W_{0}$ equals the victim's endowed wealth, $E(x)$ the victim's expenditures on safety inputs $\left(E_{x} \geq 0\right.$ and $\left.E_{x x} \geq 0\right)$, and vy the victim's contingent payments for professional rescue services where $\mathrm{v}$ is the average price per unit of this service.

Before deriving the optimal values for $\mathrm{x}$ and $\mathrm{y}$, and related implications, we consider the operation of a competitive rescue industry and the constraints it imposes on the victim's choice of rescue inputs.

2. The Rescuer. We assume that (1) rescue services are sold by a competitive industry for a fee contingent on a successful rescue; (2) each firm maximizes expected profits; (3) firms have identical entry prices; (4) there is a sufficiently large number of rescue firms (including potential entrants) to generate an industry marginal cost curve that is constant and equal to $\mathrm{mc}$; and (5) provisionally, the potential victim buys rescue services from a single firm and the latter sells services exclusively to this victim. 
Competition among rescuers for victims will drive the expected price for rescue services in equilibrium to $p_{i}^{r} v_{i}=m c$ where $p_{i}^{r} v_{i}$ equals a particular probability-price combination to the ith victim. Because of the contingent fee system, $v_{i}$ will be a multiple $\left(1 / p_{i}^{r}\right)$ of marginal cost; i.e., the lower the probability of rescue, the greater will be the ratio of price to marginal cost. Different buyers may pay different prices in a competitive equilibrium but these differences are offset by compensating variations in $p_{i}^{r}$ to maintain a constant $p_{i}^{r} v_{i}$ across buyers.

The rescue firm's expected profits are defined as

$$
\pi=p_{i}^{r} v_{i} y_{i}-c\left(y_{i}\right)
$$

where $p_{i}^{r} v_{i} y_{i}$ and $c\left(y_{i}\right)$ are expected revenue and total costs respectively: 11 Maximizing (4) with respect to y (and deleting the subscript i) yields

$$
p_{y}^{r} v y+p^{r} v+p^{r} y\left(\partial v / \partial p^{r}\right) p_{y}^{r}-c_{y}=0 \text {. }
$$

Competition forces each rescue firm to internalize the indirect effect of $y$ on $v$ due to $y^{\prime} s$ impact on the probability of a successful rescue. Since the firm is constrained by the competitive bids of other potential rescuers, its expected price cannot exceed marginal cost and its profits must be zero in equilibrium. To obtain a contract, the rescue firm must offer in response to an increase in $\mathrm{p}^{r}$ a compensating change in $\mathrm{v}$ of $-v / p^{r}$ (i.e.,$\left.\partial v / \partial p^{r}=-v / p^{r}\right)$ which maintains expected price constant and equal to marginal cost. Thus (5) simplifies to

$$
p^{r} v-C_{y}=0 \text {, }
$$

11. Peter Diamond has pointed out an awkwardness in our description of the competitive rescue model. We assume that rescue firms sell inputs (y) to customers at a contingent price of $v$ rather than sell an output (the probability of rescue) at a particular price. The former requires the seller to communicate information on technology (that is, the relationship between inputs and the probability of rescue) to the customer which differs from the ordinary competitive case where the buyer need not know anything about the seller's technology. Although we have not done so, our model could be reformulated to allow rescue firms to offer customers a probability of rescue at a contingent price $\mathrm{V}(=\mathrm{vy})$. The reformulation, however, would not alter the results of our analysis. 
The result of the foregoing analysis--that victims pay lower rather than higher prices as the probability of rescue rises--is only superficially paradoxical. In contrast to paying in advance for services, payment here is contingent on rescue. The higher the probability of rescue, the more certain payment is. The rescue firm will therefore charge a lower price per unit of rescue service, since collection is more likely. The lower the probability of rescue, the higher will be the price charged, to compensate the rescuer for the greater probability that the rescue will be unsuccessful and that he will therefore not recoup his expenditures. However, the price per rescue (vy) is higher in the higher- than in the lower-probability case, because the amount of rescue inputs purchased is greater in the former; ${ }^{12}$ it is only the price per rescue input $(v)$ that falls as the probability of rescue increases.

The assumption of contingent payment that drives our model to this result may seem an artificial one. However, this is the method of payment employed in an important branch of rescue law, the law of salvage, where we shall see that it may well be more efficient than alternative methods.

The extension of the analysis to the case of the rescue firm that sells services to more than a single victim is straightforward. In 12. The price per rescue (vy) will be a positive function of $p^{r}$ if $\partial(\mathrm{vy}) / \partial \mathrm{y}>0$. Letting $\mathrm{e}_{\mathrm{py}}$ equal the elasticity of $\mathrm{p}^{r}$ with respect to $\mathrm{y}$, we have $\partial(v y) / \partial y=v\left(1-e_{p y}\right) \gtrless 0$, according to whether $e_{p y} \lesseqgtr 1$. Since the equilibrium condition of equation (9) may be rewritten as $e_{p y} L_{o}-$ $v y=0$ and $I_{0}-v y$, the net value of rescue, is positive (otherwise no rescue inputs would be purchased), $e_{\text {py }}$ must be less than $I$ and hence $\partial(v y) / \partial y>0$. 
equilibrium, the firm would be selling at a different price ( $v$ ) to each customer, offset by an appropriate compensating change in $\mathrm{p}^{\mathrm{r}}$; that is, higher-probability rescues would be sold at lower prices per unit of $\mathrm{y}^{13}$

3. Optimality Conditions. We assume that victims are risk neutral. Therefore, maximizing expected utility is equivalent to minimizing the expected loss from the hazard $(\bar{L})$ where

$$
\bar{L}=E(x)+p^{h}\left(1-p^{r}\right) L_{0}+p^{h} p^{r} \text { vy. }
$$

Maximizing (7) with respect to $\mathrm{x}$ and $\mathrm{y}$ yields

$$
\begin{aligned}
& p_{x}^{h}\left[\left(1-p^{r}\right) L_{0}\right.\left.+p_{r} v y\right]+E_{x}=0 \\
&-p_{y} L_{0}+p^{r} v=0,
\end{aligned}
$$

noting that (9) takes account of the compensating change in $v$ when $p^{r}$ changes in response to $\mathrm{y}$. In (8) $\mathrm{E}_{\mathrm{x}}$ denotes marginal cost and the remaining set of terms equals the expected marginal returns from safety inputs. Marginal returns include the savings in expected losses $\left(\left(1-p^{r}\right)_{0}\right)$ if the hazard occurs and rescue fails and the savings in resources allocated to rescue if the hazard is avoided ( $p^{r} v y$, which from $(6)$ and the assumption of constant marginal cost equals $\mathrm{C}(\mathrm{y})$ ). Similarly, in equation (9), $\mathrm{p}^{\mathrm{r}} \mathrm{v}$ is the marginal cost to the victim of $\mathrm{y}$ (which is also the rescuer's marginal revenue and cost in equilibrium), and $\mathrm{p}_{y} \mathrm{r}_{0}$ is the expected marginal returns from rescue. ${ }^{14} \mathrm{~L}_{0}$ can be interpreted as the gross value of a successful

13. The case where many firms provide rescue services to a single victim is more complicated because we must take account of the possibility that the rescue firm will incur costs to discovar the victim's location but will arrive at the scene of the disaster after rescue has been successfully completed by another firm; this extension of the analysis is not treated systematically in this article.

14. The second order conditions for a minimum are satisfied by our assumption that $\mathrm{p}_{\mathrm{xx}}^{\mathrm{h}}>0, \mathrm{p}_{\mathrm{yy}}^{\mathrm{r}}<0, \mathrm{E}_{\mathrm{xx}} \geq 0$, and $\mathrm{C}_{\mathrm{yy}}=0$. 
rescue (i.e., the difference in wealth between the rescue and nonrescue states before deducting expenditures on rescue) and $L_{0}$ - vy the net value. The latter must be positive; otherwise the victim would have had no incentive to purchase any inputs of $y$ in the first place. The equilibrium levels of $x$ and $y$ obtained in equations (8) and (9) are socially optimal. No externalities or monopoly elements are present, and the levels of $x$ and $y$ obtained are identical to those that would result if the victim of the hazard and the rescue firm merged to form a single enterprise. 15

The effects of exogenous changes on the equilibrium conditions are easily derived. An increase in $\mathrm{L}_{\mathrm{O}}$ increases the marginal returns from both safety $(x)$ and rescue $(y)$, leading the victim to increase his purchase of both inputs. An increase in the marginal costs of safety reduces safety but has no impact on rescue inputs. However, an increase in the marginal costs of rescue (an increase in $\mathrm{p}^{\mathrm{r}} \mathrm{v}$ in equilibrium) not only reduces rescue inputs but also leads the victim to substitute toward his own safety inputs. Consider the case of two victims, $A$ and $B$, who differ only in that $A$ has a higher potential loss than B. In equilibrium, A will utilize more inputs of $x$ and $y ; p^{h}$ : will be lower and $p^{r}$ higher for $A$; and, if $A$ is rescued, he will pay a lower price per unit of rescue services but a higher total price for the rescue, Finally, suppose the hazard arose from the negligence of a third party. Since the latter is liable for the loss, $\mathrm{L}_{0}$, he will have an incentive to keep purchasing

15. The expected loss from the joint enterprise is obtained by combining equations (4) and (7). Minimizing this function with respect to $\mathrm{x}$ and $\mathrm{y}$ yields equations (8) and (9). 
inputs of $y$ until the expected reduction in liability costs, which equals $\mathrm{p}_{\mathrm{y}}^{\mathrm{r}_{\mathrm{o}}}$, is equal to the marginal costs of rescue. Obviously, the optimal purchase for the tortfeasor is given by equation (9), which is also the socially efficient purchase.

The equilibrium share $\left(s^{*}\right)$ of the gross value of the rescue, $L_{0}$, received by the successful rescuer equals

$$
\mathrm{s}^{*}=\mathrm{e}_{\mathrm{py}}
$$

where $e_{p y}$, the elasticity of $p$ with respect to $y$, is less than 1 . Since the ratio of the rescuer's to the victim's share in the gross value is $e_{p y} /\left(1-e_{p y}\right)$, the rescuer's share will exceed, equal, or be less than the victim's share depending on whether $e_{p y}$ is greater, equal, or less than one-half.

4. Transactions Costs and Professional Rescue. When the costs of negotiating rescue contracts are relatively low and there are a sufficiently large number of potential rescuers, the voluntary-exchange model developed above will generate a socially efficient allocation of resources to safety and rescue. From an economic standpoint, there would be no justification for special legal rules applicable to rescues; ordinary contract law would be sufficient. And in fact many rescue situations do not involve high transaction costs, as in the following examples:

1. Dr. Jones sees Smith lying injured on the street and offers him medical services. Smith is both conscious and lucid. He may accept the doctor's offer, in which case the standard patient-doctor contractual relationship applies; or he may refuse, stating that he has made other arrangements.

2. The Acme Roofing Company is patching Smith's roof when a tree falls on the house, leaving a large hole in Smith's roof that if unattended 
will result in substantial water damage to the home and its furnishings. Smith is visiting his in-laws for a week and has left Acme the telephone number where he can be reached.

3. A ship is in peril but is docked in the harbor and there is no immediate danger of its sinking (nor is there any immediate danger to surrounding ships). Another ship, which is equipped to perform salvage services, is available for hire and there is ample time for negotiation between the owners of the two ships.

If in any of these examples the rescuer provides his services either explicitly against the wishes of the victim or without first consulting him, and then later claimed a fee, the law will disallow the claim (assuming the purpose of the law is to promote economic efficiency). To enforce the claim would have the effect of encouraging coerced exchanges, a second-best alternative to voluntary exchanges that is justifiable only where the costs of voluntary exchanges are prohibitive. ${ }^{16}$ In each of the above cases the claim for compensation would in fact fail.

Now let the circumstances be somewhat different in the three examples:

16. See Guido Calabresi \& A. Douglas Melamed, Property Rules, Liability Rules, and Inalienability: One View of the Cathedral, 85 Harv. L. Rev. 1089 (1972).

The analysis in the text enables us to assign a precise economic meaning to the legal concept of "officiousness," a frequent ground for denying a claim for restitution based on unbargained assistance. In economic terms, an "officious" tender of assistance is one that occurs in a setting of low transaction costs. Since a coerced exchange is inefficient in such a situation, the law should refuse to enforce it; the label "officious" is rightly attached to an individual who has attempted to coerce an exchange in circumstances where coercion is not justified by high transaction costs. 
Smith, in refusing Dr. Jones' offer of assistance, was speaking in a daze as a result of the accident; or he was unconscious, and therefore incapable of either accepting or refusing the doctor's offer. No longer is a voluntary transaction between Smith and Jones possible; the costs of such a transaction are prohibitive because of Smith's incapacity. ${ }^{17}$ In the roof-damage example, suppose Smith and his family were on a camping trip in Europe when the tree fell on his house. And in the ship example suppose the peril was a fire aboard ship and the ship was in immediate danger of sinking; exigencies of time now preclude the negotiations required to agree on the terms of a voluntary purchase of rescue services. ${ }^{18}$

Even where there is both mental capacity and adequate time for negotiating, the process of voluntary exchange may not work efficiently. Suppose the sinking ship is far out at sea--though in no immediate danger of sinking--and a potential rescuer comes upon it by chance or by responding to its distress signal. There is time for negotiation but little likelihood of another ship's chancing on the scene. The potential rescuer therefore has a monopoly position which he can use to try to extract the victim's promise, prior to initiation of any rescue efforts, to pay him all or most of the value of the ship and cargo. At the same time, because the rescuer has no alternative customer for his rescue services at the place where he has found the ship in distress, the "rescuee" has a monopoly position,

17. Likewise if Smith were lucid but a ycung child and his parents could not be notified.

18. The problem of inadequate time in an emergency is an aspect of the traditional economic concern with large numbers as a source of high transaction costs. It is the large number of potential rescuers ex ante that prevents the shipowner from entering into rescue contracts in advance with everyone who might some day be in a position to rescue the ship. 
making the situation one of bilateral monopoly. Transaction costs under bilateral monopoly are high because there is a range of possible prices which invites haggling. The haggling may be protracted, costly, and sometimes unsuccessful in producing agreement on terms.

5. Size of Reward in the High Transaction Cost Professional Rescue Case. To identify a set of rescue problems in which the costs of voluntary tranacting are high is not, of course, to justify legal intervention (as we shall see, the costs of intervention may be disproportionate to the benefits, or altruism may provide an acceptable substitute for legal compulsion), or to prescribe the form of such interventions (e.g., liability versus restitution). Postponing these questions, we consider here at what level compensation to a successful rescuer should be set in cases where he is entitled to compensation as a matter of either contractual agreement or law. Suppose, for example, that a successful rescuer at sea is attempting to enforce a contract calling for the transfer to him of the entire value of the property rescued, or that Dr. Jones is claiming that, but for his timely services, Smith (unconscious at the time of the rescue) would have died, and therefore Jones should be given Smith's entire wealth. Enforcement of such terms would lead to an inefficient allocation of resources to safety (the $\mathrm{x}$ inputs in our model) and/or rescue (the $\mathrm{y}$ inputs); we predict, therefore, that legal rules to enforce such terms would not emerge.

When the rescuer receives $\mathrm{L}_{0}$, the value of the ship and cargo or Smith's wealth, and this is anticipated by the victim, the first order condition for the optimal purchase of safety by the victim (equation (8)) becomes

$$
\mathrm{p}_{\mathrm{x}}^{\mathrm{h} \mathrm{L}_{0}}+\mathrm{E}_{\mathrm{x}}=0
$$


Since $L_{0}$ exceeds the sum of $\left(1-p^{r}\right) L_{0}+p^{r}$ vy in equation (8) (otherwise the victim would not have contracted for rescue inputs in the competitive case), the expected marginal returns for safety are greater in (11) than (8). Therefore, the victim will be led to a socially excessive purchase of safety inputs. Victims will be too safe, fearing that in the event of trouble they would lose everything. ${ }^{19}$

Although too few hazards would occur, giving the entire value of the property rescued to the rescuer would at least generate the optimal inputs of rescue $(y)$ once a hazard had occurred. Expected monopoly profits are maximized when $\mathrm{p}_{\mathrm{y}} \mathrm{r}_{\mathrm{o}}-\mathrm{C}_{\mathrm{y}}=0$, which yields the identical level of expenditures on $y$ that the victim makes in the competitive case (see equation (9), noting that from (6) $\mathrm{C}_{\mathrm{y}}$ can be substituted for $\left.\mathrm{p}^{\mathrm{r}} \mathrm{v}\right) \cdot{ }^{20}$ Put differently, when the rescuer receives the full value saved, he behaves as if he were the victim because the victim's loss is identical to the rescuer's forgone

19. A similar point is made by Peter A. Diamond \& James A. Mirrlees, supra note 9 .

The problem of excessive investment in safety by victims would be eliminated if the reward were paid by the state rather than by the victim. Another problem would be created, however: victims would invest too little from a social standpoint in safety since the costs of rescue would not be borne by them. We do not consider further in this paper the properties of a public system of rewards to encourage rescues; nor will our discussion of altruistic rescues consider the form of altruism that consists of a stranger's offering rewards to rescuers, as in Andrew Carnegie's "Hero Fund." See Joseph Frazier Wall, Andrew Carnegie 894-97 (1970).

20. Maximization of expected profits in the initial monopoly equilibrium will yield positive expected profits if $\mathrm{e}_{\mathrm{py}}<1$. And we have already shown that the level of $\mathrm{y}$ that satisfies the competitive equilibrium (equations (8) and (9)) requires an elasticity less than 1. The paradox that expected profits are zero in the competitive case when $p_{y}^{\frac{r_{L}}{r_{0}}}-C_{y}$ but positive in the monopoly case at this same point is due to the compensating change in $\mathrm{v}$ under competition that is absent under monopoly. 
revenue from an unsuccessful rescue. 21

To take the analysis one step further, suppose that in the course of a rescue at sea the rescuer expends more than the salvage value of the ship $\left(\mathrm{L}_{0}\right)$. Should the legal system grant him a right to recover his full costs? On efficiency grounds, the answer is no. The rescuer expended resources beyond the point where marginal costs equal expected marginal returns. ${ }^{22}$ To grant full reimbursement would induce other rescuers (and victims) in the future to allocate a socially excessive amount of resources to safety and rescue.

Our conclusion, which is similar though not identical to that of Diamond and Mirrlees, ${ }^{23}$ is that in a setting of high transaction costs,

21. Suppose, however, that rescue inputs consist of both inputs to locate the victim $\left(\mathrm{y}_{1}\right)$ and inputs to rescue him $\left(\mathrm{y}_{2}\right)$ once he is located. The rescuer has a monopoly after he has located the victim but there is competition among rescuers to locate him. Hence the level of $y\left(=y_{1}+y_{2}\right)$ that satisfies $p_{y} L_{0}-C_{y}=0$ will not be an equilibrium one because it will violate the zero profit condition of a competitive equilibrium. The prospects of receiving the full value of the rescue would induce firms to increase their inputs of $y$ (by increasing $y_{1}$ ) until $p^{r_{L}} L_{o}-C(y)=0$, that is, beyond the socially efficient level. Thus monopoly, in the sense of a legal entitlement to the full value preserved by the rescue, would induce socially excessive spending on both safety and rescue. Of course, if monopoly were assumed to result from a purely chance finding of the victim (for example, if $y_{1}$ is constrained to equal 0 ), then the only inefficiency would be the excessive spending on safety.

An alternative way of modelling the problem would be to write the probability of rescue as $\mathrm{p}^{\mathrm{r}}=\mathrm{p}^{\mathrm{r}}(\mathrm{N}, \mathrm{y})$ where $\mathrm{N}$ is the number of firms and $\mathrm{y}$ is the rescue inputs by the firm that has located the victim. Presumably, the more firms searching for the victim, the more likely he is to be located and the greater $p^{r}$ (that is, $p_{n}^{r}>0$ ). The full equilibrium would then produce a socially excessive number of firms. This result is analogous to the equilibrium under monopolistic competition.

22. Since expected losses from the hazard equal $\left(I-p^{r}\right) L_{0}+C(y)$, expenditures on $\mathrm{y}$ that exceeded $\mathrm{L}_{\mathrm{o}}$ would yield a higher expected loss than if no rescue efforts had heen attempted in the first place, no matter how productive were these expenditures.

23. See note 9 supra. 
and disregarding as do they the possibility of altruistic motivation for rescues, it would be inefficient to give the rescuer either no legal right to a reward or a right to a reward equal to the value of the life or other thing saved. Diamond and Mirrlees do not consider the possibility of another alternative, which is to calculate the reward that would have been negotiated in a competitive rescue market. The model developed in this part of our paper provides the set of variables (the amount of loss, the quantity of the rescue inputs, their opportunity costs, the probability of a successful rescue, etc.) relevant to determining the optimal price and the quantity of rescue inputs. As we shall see in Part II, this model approximates the actual approach used by the courts in hightransaction-cost maritime-rescue cases.

B. The Economics of Altruistic Rescue ${ }^{24}$

We define a rescuer as altruistic if he is willing to supply rescue services in the absence of any expectation of being compensated for doing so. Compensation could take many forms besides money--such as public recognition as an altruist, or an enhanced probability that the rescuer would himself be rescued (by the person he rescued or by another) should he at some future time find himself in peril. Altruism motivated by expectation of future benefits, "reciprocal altruism" as it is called, is probably unimportant in most present-day rescue settings involving strangers: the chance that $B$, whom $A$ pulls out of the lake, will one day be in a position to provide a reciprocal service to $A$ will ordinarily be too remote to motivate

24. See also William M. Landes \& Richard A. Posner, Altruism in Law and Economics (forthcoming, in Am. Econ. Rev., May 1978). 
$A$ in rescuing $B$. We shall therefore ignore reciprocal altruism. ${ }^{25}$

The recognition factor is present in many altruistic transactions. Anonymous gifts to charity, to family members, etc., are relatively infrequent. Charities make every effort to give wide currency to large gifts-and to identify prominently the donors. Foundations commonly carry the name of their founder, university chairs the name of the donor. Prospective donors negotiate, sometimes fiercely, with universities, hospitals, and other charitable institutions over the price of naming the donor on a building or a room. These observations are relevant here because, as we shall see, some methods of promoting rescues, notably imposing legal liability for nonrescue, may reduce the public recognition accorded the altruistic rescuer and by so doing, we predict, reduce the number of altruistically motivated rescues. However, in the development of our formal model of altruistic rescue we shall ignore the recognition factor (to which we return later in the paper). The formal model is one of altruistic rescue in its purest sense, $\underline{i . e}$. , devoid of all expectation of any form of compensation.

1. A Model of Altruism. When a hazard arises that lowers the endangered person's expected wealth, perhaps very dramatically, the rescuer's utility, $U^{r}$, becomes a function in part of the welfare of the endangered person (victim). The rescuer's utility can then be increased by an appropriate expenditure (of time, or whatever) on attempting to rescue the victim and thereby reduce the victim's expected loss.

25. Reciprocal altruism could be quite important in small communities. This may be the kernel of truth in the widespread view that altruistic rescue is less frequent in modern urban societies. See Alan Barth, The Vanishing Samaritan, in The Good Samaritan and the Law 159 (James M. Ratcliffe ed. 1966). 
We assume for convenience that $U^{r}$ is additive with respect to the rescuer's wealth and to the victim's expected wealth as in

$$
U^{r}=g\left(W^{r}-C(y)\right)+h\left(W^{v}-\left(1-p^{r}\right) L_{0}\right)
$$

where $\mathrm{W}^{r}$ and $\mathrm{W}^{\mathrm{V}}$ are, respectively, the rescuer's and victim's endowed wealth, $C(y), p^{r}$ and $L_{0}$ are defined as before, and $g$ and $h$ are respectively the utility to the rescuer of his wealth and of the victim's expected wealth. 26 Maximizing $\mathrm{U}^{\mathrm{r}}$ with respect to y yields

$$
\left(\mathrm{h}^{\prime} / \mathrm{g}^{\prime}\right) \mathrm{p}_{\mathrm{y}}^{\mathrm{r}_{\mathrm{o}}}-\mathrm{C}_{\mathrm{y}}=0
$$

where $\left(h^{\prime} / g^{\prime}\right)$ equals the marginal degree of altruism, $\underline{\text { i.e. }}$, the rate at which the rescuer is willing to exchange dollars of his wealth for a dollar increase in the victim's expected wealth to keep $U^{r}$ constant.

Equation (13) implies that (1) the greater is the degree of altruism at the margin, other things being held constant, the greater will be the altruist's inputs of rescue services $(y)$; (2) the greater is $L_{0}$, the greater will $\mathrm{y}$ be because of both (a) the direct effect on marginal returns and (b) the indirect effect via the increase in $h^{\prime}$; (3) the more productive the altruist's rescue inputs are, the greater will $\mathrm{p}_{\mathrm{y}}^{\mathrm{r}}$ be for a given $\mathrm{y}$ and the greater will $y$ be; and (4) the lower the marginal costs of rescue, the greater will be $\mathrm{y}$ as both $\mathrm{C}_{\mathrm{y}}$ and $\mathrm{g}$ ' decline (for a given $\mathrm{y}$ ).

Qualitatively, results (2) - (4) are identical to those derived from our model of professional rescue. This is because altruism acts as a substitute for compensation, inducing the rescuer to behave as if the victim's expected loss, weighted by $\mathrm{h}^{\prime} / \mathrm{g}^{\prime}$, were the rescuer's loss. In

26. We assume risk neutrality of the altruist with respect to the victim's expected loss and positive and diminishing marginal utility to the altruist of his and the victim's wealth $\left(g^{\prime}>0, g^{\prime \prime}<0, h^{\prime}>0\right.$ and $\left.h^{\prime \prime}<0\right)$. 
the special case where the altruist is indifferent between a dollar increase in his wealth and a dollar reduction in the victim's expected loss $\left(h^{\prime} / g^{\prime}=1\right)$, altruism would be a perfect substitute for a nonaltruistic competitive market in rescue services. Both would lead to an allocation of resources to rescue that minimized the net expected loss from the hazard. If $h^{\prime} / g^{\prime}$ were greater than one in equilibrium, altruism would generate a greater quantity of services than would a nonaltruistic competitive market.

2. Altruistic Versus Compensated Rescue. Since the enforcement of a legal claim for compensation is costly even if the claim is settled rather than litigated, we predict that a legal system concerned with maximizing efficiency would refuse to grant compensation in rescue situations where altruism provided a strong inducement to rescue attempts. If $h^{\prime} / g^{\prime}$ in equation (13) were $\geq 1$ (or even somewhat $<1$ once administrative costs are considered), altruism by itself would induce the allocation of the efficient amount of resources to rescue attempts. 27 A legal rule entitling the rescuer to compensation in these situations would be inefficient because it would substitute a costly legal transaction for a costless altruistic exchange. It is no reply that the altruist would refuse compensation, so that the costs of administering a legal compensation scheme would be limited to the subset of rescues carried out by nonaltruists (…e. , persons providing services only if compensation is expected), and therefore a legal entitlement to compensation is always the preferred rule. There is no presumption

27. By "efficient" we mean a level of y under altruism greater than or equal to $\mathrm{y}^{*}$, where $\mathrm{y}^{*}$ minimizes the expected losses from the hazard. Thus, $\mathrm{y}^{*}$ would be the equilibrium quantity of $y$ in a competitive rescue market with no transaction costs when altruism is absent. The reason a level of $y>y^{*}$ is also efficient when altruism is present is that the increment beyond $y^{*}$ represents a gain in utility to both the rescuer and victim (though the expected loss from the hazard, $c(y)+\left(1-p^{r}\right) L_{0}$, rises $)$. 
that after the rescue the altruist will continue to behave altruistically towards the victim. Once the peril has passed the victim's expected wealth will have risen $\left(W^{v}>W^{v}-\left(1-p^{r}\right) L_{0}\right)$, and the altruistic impulse will therefore diminish greatly or cease as $\mathrm{h}^{\prime} / \mathrm{g}^{\prime}$ approaches zero. Thus, assuming strong altruistic motivations to rescue, a general rule permitting compensation would induce altruistic rescuers to claim compensation, creating heavy administrative costs but only a small increase in the resources allocated to rescue.

Several broad classes of rescue cases can be identified in which a legal entitlement to compensation would probably be an unnecessary inducement to rescue, and possibly, therefore, inefficient as well. The most obvious are those situations where the rescuer and victim have a strong personal relationship prior to the rescue (e.g., family members, close friends, members of the same combat unit in battle). Here the value of $h^{\prime} / g^{\prime}$ is likely to be near unity for a wide range of expenditures on rescue, in which event altruism alone would be a sufficient inducement to rescue. ${ }^{28}$ Less obviously, $\mathrm{h}^{\prime} / \mathrm{g}^{\prime}$ may be close to unity even though the rescuer and victim are strangers, provided the losses to the victim are great and the costs to the rescuer are slight. This follows from equation (13) where $h^{\prime} / g^{\prime}$, and hence the marginal returns from rescue, are greater the greater the victim's loss (from the assumption of diminishing marginal utility to the rescuer of the victim's expected wealth) and the smaller the equilibrium

28. An additional reason for not having to allow legal claims to compensation in rescues involving family members, members of the same fighting unit, etc., is that the continuing relationship between the parties increases the likelihood of reciprocal altruism. Put differently, the rescue is the basis of a beneficial exchange of present rescue services for future rescue services to be provided by the present victim to the present rescuer. 
expenditure on rescue (from the assumption of diminishing marginal utility of the rescuer's wealth). For example, suppose the victim is in grave peril of death which can be averted at the cost of a phone call (the opportunity cost of a few minutes plus $20 \not$ ) to the rescuer. The rescuer. can bring about a very substantial transfer at a trivial cost to himself; the effect is that of a huge matching grant, or of allowing a charitable deduction in an income tax system with very high marginal rates.

When the costs of administering a compensation scheme are taken into account, there is a further class of rescue situations in which compensation is likely to be inefficient. Consider the situation of a drowning person crying for help off a crowded beach. His rescue may require the cooperative efforts of several persons, in which case the costs of sorting out the legal claims of the various parties could be large. Moreover, the degree of altruism is likely to be substantial in these cases. The altruist's utility is independent of the benefits to other persons from the reduction in the victim's expected loss. Because the gain to each altruist does not depend on the gains received by others, a reduction in the loss is a pure public good.

If we put to one side potential free-rider problems and assume that altruistic rescuers cooperate and agree on a cost-sharing scheme, then the market equilibrium for the $n$ altruists $(i=1, \ldots, n)$ requires that

$$
\left(\sum h_{i}^{\prime} / \bar{g}^{\prime}\right) p_{y}^{r_{L}} L_{0}-c_{y}=0
$$

where $\vec{g}$ ' is the average of the marginal utilities of each rescuer's wealth weighted by his share $\left(\lambda_{i}\right)$ in total rescue cost $\left(\underline{i . e} ., \bar{g}^{\prime}=\sum g_{i}^{\prime} \lambda_{i}\right){ }^{29}$ Thus,

29. The utility function of the ith altruist can be written as

$$
u_{i}^{r}=g_{i}\left(w_{i}^{r}-\lambda_{i} c(y)\right)+h_{i}\left(w^{v}-\left(1-p^{r}\right) L_{0}\right)
$$

Each altruist would be in equilibrum when 
as the number of cooperating altruists increases, the expected marginal returns aggregated over all rescuers increases as $\sum_{\mathrm{h}} ! / \overline{\mathrm{g}}$ ' increases and the amount of rescue inputs will rise. Further, the marginal returns from rescue are likely to rise at a proportionately faster rate than the increase in the number of rescuers. ${ }^{30}$ This suggests that the combined altruism of a modest number of rescuers (e.g., a group of swimmers, campers or mountain climbers) may generate a level of rescue inputs that would equal or exceed the amount generated were the rescuer entitled to compensation.

If, contrary to our assumption, free-rider problems are severe when there is a group of rescuers, the appropriate rule from an efficiency standpoint is unclear. On the one hand, free-rider problems reduce the effectiveness of altruism in generating rescue inputs. On the other hand, the costs of administering legal claims to compensation are likely to

\section{$\overline{29 \text { continued }}$}

$$
-g_{i}^{\prime} \lambda_{i} C_{y}+h_{i}^{\prime} p_{y}^{r_{L}}=0
$$

The market equilibrium would require us to solve the $n$ equations above for $n$ unknowns ( $y$ and the $\left.(n-1) \lambda_{j}^{\prime} s\right)$. The equilibrium share $\left(\lambda_{i}\right)$ of total costs paid by each altruist woutd be proportional to his marginal degree of altruism, $h_{i} / g_{i}^{\prime}-$ that is, the ith altruist's share would be greater, the smaller the marginal utility of his own wealth and the greater the marginal utility to the altruist of the victim's expected wealth.

30. Suppose all altruists were identical. Then the log of marginal returns in (14) could be written as

$$
\text { In }\left(n h^{\prime}\right)-\ln g^{\prime}+\ln \left(p_{y}^{r_{0}}\right)
$$

and the elasticity of marginal returns with respect to $n$ would equal

$$
1-\frac{\partial \ln g^{\prime}}{\partial \ln n} \text {. }
$$

Since $g^{\prime}$ falls with an increase in $n$ because of the reduction in expenditures per altruist for a given market quantity of $y$ and the assumption of diminishing unity. If we relax the assumption of identical altruists and assume that rescuers are randomly selected from a distribution of rescuers who differ in their altruism, then we would replace $h^{\prime}$ and $g^{\prime}$ above by their expected or mean values. But the conlcusion that the elasticity is greater than one would
still hold. 
be greater when free-rider problems are present because the compensation must be paid to a large number of people.

In many situations altruistic motivation is unlikely to be sufficient to induce an efficient level of rescues--in particular, where either the loss from failure to rescue is relatively small or the cost of rescue relatively high. An important example of the latter problem is the case of commercial rescue. Business firms, espeically in a competitive market, are less likely to act altruistically than individuals. As an extreme example, take the competitive firm that hires rather than owns any scarce factors of production, and under short-term contracts too, so that it has no rents. To such a firm the consequence of altruism (i.e., an uncompensated addition to its marginal costs) would be exit from the market because its supply curve would be pushed everywhere above its (horizontal) demand curve, unless altruism were uniformly characteristic of the firms in the market. But that is unlikely; altruism like discrimination has negative survival value under competition and would tend to be weeded out of competitive markets. While the example is extreme, it illustrates the tendency of altruism to be crowded out by selfishness in competitive markets.

The focus thus far in this section has been on compensation versus altruism as methods of motivating rescue. These approaches need not be mutually exclusive, but that depends on the extent to which compensation might induce substitution away from altruistically motivated rescues. 31

31. This question is similar to one discussed by Richard Titmuss in his well-known study comparing the workings of the commercialized blood system in the United States to the voluntary system in Britain. Richard Titmuss, The Gift Relationship: From Human Blood to Social Policy (1971). Titmuss's attack on a market in blood rests in part on his belief that "the commercialization of blood and donor relationships represses the expression of altruism. . . ." 
To analyze this question, assume the law requires victims to reimburse successful rescuers at a price per unit of input equal to marginal cost divided by $\mathrm{p}^{\mathrm{r}}$. Victims, however, are required to reimburse rescuers only up to the quantity of inputs, $\mathrm{y}^{*}$, that minimizes the expected loss from the hazard. ${ }^{32}$ Assume also that rescuers no longer behave altruistically once the peril is passed; hence they enforce their legal right to compensation (‥e., altruists do not view their compensation as part of the victim's loss). An alternative way to frame the analysis is to determine the amount of altruistic rescue services provided when there is a class of nonaltruists who are willing to provide rescue services at expected prices equal to marginal cost and when victims purchase $\mathrm{y}^{*}$ from these (professional) rescuers. Without compensation let altruism initially produce a level of rescue inputs of $\mathrm{y}_{0}$ where $\mathrm{y}_{0}<\mathrm{y}^{*}$. When legal compensation is instituted, assume that $\mathrm{y}^{*}$ is initially provided. Will the existence of altruism lead to any additional rescue inputs beyond $y^{*}$ ? Since at $y^{*}$ both $p_{y}^{r_{0}}-C_{y}=0$

31 continued

Id. at - Titmuss does not provide an explanation of why a market drives out altruism, and has been criticized for this omission in several reviews by economists. See for example, Kenneth Arrow, Gifts and Exchanges, in Altruism, Morality, and Economic Theory (Edmund S. Phelps ed. 1975). Although our analysis suggests that Titmuss's proposition is not inconsistent with economic theory, the empirical validity of the proposition is far from certain. See Harvey M. Sapolsky \& Stan N. Finkelstein, Blood Policy Revisited-A New Look at "The Gift Relationship," Pub. Interest, Winter 1977, p. 15.

32. This implies that victims buy rescue services until $-p_{y}^{r_{0}}+p^{r} v=0$ (see equation $(9))$. Since competition. requires that $\mathrm{p}^{r} \mathrm{v}-\mathrm{C}_{\mathrm{y}}=0$ (see equation (6)), it follows that victims purchase rescue services until $v=C_{y} / p^{r}$. 
and the expected wealth of the altruist is $w^{r}, 33$ the value of $h^{\prime} / g^{\prime}$ would have to be greater than one for the first dollar of additional rescue services provided beyond $\mathrm{y}^{*}$. Put differently, legal compensation will eliminate all altruistic rescue inputs ( $\underline{\text { i.e. }}$. , inputs not paid for) at $\mathrm{y}^{*}$ unless the altruist values an expected increase in the victim's wealth by more than he values a dollar loss in his own wealth (i.e., h'/g' must be greater than one for additional inputs to be provided). 34 Whether $\mathrm{h}^{\prime} / \mathrm{g}^{\prime}$ is < or > 1, a legal right to compensation will always induce a substitution away from altruistically supplied rescue inputs. In the former case, the substitution will be total; no altruistic rescue inputs will be supplied. In the latter case, some altruistic inputs will be supplied but substitution will also take place since the net increase in rescue inputs must be less than $\mathrm{y}^{*}$, the quantity that is now paid for. 35

33. If the altruist were providing $\mathrm{y}^{*}$, his expected compensation would just offset his expenditures on $y^{*}$ and thus his wealth would be $W^{r}$. (We assume the altruist is risk neutral.) Obviously, if $\mathrm{y}^{*}$ were being provided by a nonaltruist, the wealth of the altruist would also be $\mathrm{W}^{\mathrm{r}}$ when $\mathrm{y}^{*}$ is being provided.

34. An alternative formulation, however, would generate a different result. Suppose it were possible for the altruist and the victim to negotiate for the provision of additional rescue inputs beyond $\mathrm{y}^{*}$. At $\mathrm{y}^{*}$ the victim values additional inputs somewhat less than $p_{y^{*}}^{r} \mathrm{~L}_{0}$, and the rescuer values them at $\left(h^{\prime} / g^{\prime}\right) p_{y^{*} L_{0}}^{r}$. Thus the combined value for an input beyond $y^{*}$ would equal the sum of the victim's and altruist's valuation, and additional inputs would be provided until the sum of their valuations equalled the marginal cost. This could be termed a "first best" solution. Since our analysis explicitly rules out negotiation between the parties, the only relevant demand for inputs beyond $\mathrm{y}^{*}$ is that of the altruist.

35. Suppose the net increase were equal to $y^{*}$. Since the altruist would then be supplying $y_{0}$ inputs, his expenditures on rescue inputs would be unchanged and hence $g^{\prime}$ would equal its initial (pre-compensation) value. Since both $h^{\prime}$ and $p_{y}^{r}$ are lower when $y=y^{*}+y_{o}$ (by the assumptions of diminishing marginal utility and diminishing marginal product), we would be operating at a point where $\left(h^{\prime} / g^{\prime}\right) p_{y^{\prime}}^{r_{0}}$ was less than $C_{y}$. 
Now suppose that, in the absence of legal compensation, altruism was generating a level of rescue inputs $y_{1}>y^{*}$. Compensation in this case must generate an increase in rescue inputs beyond $y_{1}$. To see why, suppose that $\mathrm{y}_{1}$ continued to be supplied when rescuers were reimbursed for $\mathrm{y}^{*}$ inputs. Since the altruist's wealth is greater, $g^{\prime}$ would be smaller and thus $\left(h^{\prime} / g^{\prime}\right) p_{y}^{r_{0}}$ would be greater than $c_{y}$ at $y_{1}$. This, in turn, would lead to an increase in inputs beyond $y_{1}$. Again it follows that the net increase in rescue inputs must be less than $\mathrm{y}^{*}$, so that a substitution away from altruistically supplied inputs occurs once monetary compensation is instituted. 36

We have shown that a legal compensation scheme (ignoring administrative cost) will never lead to a reduction in the quantity of rescue inputs. Generally, the quantity of rescue inputs will rise when compensation is introduced, though in all our examples the net increase was less than the amount paid for $\left(y^{*}\right)$ because the provision of compensation will always induce a substitution away from altruistically provided rescue inputs. If altruistic impulses are weak, the amount of rescue inputs provided is likely to be far less than $\mathrm{y}^{*}$; in this case, even though compensation will probably eliminate altruistically motived rescues, it may be fustifiable because of its effect in encouraging nonaltruistic rescues. But in cases where altruism is substantial, not only will there be some substitution away from altruistic rescues but the net increment in rescue activities resulting from the encouragement to nonaltruistic rescuers may not be large enough to offset the administrative costs of legal compensation.

36. If the net increase were $\mathrm{y}^{*}$, both $\mathrm{h}^{\prime} / \mathrm{g}^{\prime}$ and $\mathrm{p}_{\mathrm{y}}^{\mathrm{r}}$ would be lower than at $\mathrm{y}_{1}$. Hence we would be operating where the marginal return to the altruist was less than his marginal costs, and equilibrium would require the altruist to reduce his imputs. 


\section{APPLICATIONS AND EXTENSIONS}

\section{A. Admiralty}

1. Salvage. Salvage is anything rescued from navigable waters, including ships, cargo, goods washed out to sea, and even aircraft downed at sea. A salvor is entitled to a judicially determined reward from the

owner of the property rescued. ${ }^{37}$ The circumstances in which salvage awards are allowed and the criteria governing the size of the award suggest that the purpose of salvage awards is to encourage rescues in settings of high transaction costs by simulating the conditions and outcomes of a competitive market.

The rescue must occur as a result of circumstances that have endangered the ship, its cargo, or other property. ${ }^{38}$ From an economic standpoint, the significance of the danger requirement is that it delimits situations in which (1) the loss if rescue is not attempted is likely to be substantial and (2) the chances of purchasing the rescue in a competitive market are likely to be slight. It is normally infeasible for the ship's owner to contract in advance of the voyage with all (or even some subset of most probable)rescuers. Not only would the number of contracting parties be very high but the expected danger might be too slight to warrant incurring

37. "Life salvage" is discussed later in this section. For the rules of salvage see Kenneth C. McGuffie, Kennedy's Civil Salvage (4th ed. 1958) [hereinafter Kennedy's]; Martin J. Norris, The Law of Salvage (1958). See also Grant Gilmore \& Charles L. Black, Jr., The Law of Admiralty 395-442 (2d ed 1975) [hereinafter Gilmore \& Black].

38. Dangerous circumstances include leaks, fires, being stranded, missing or broken equipment (e.g., a damaged propeller), incapacity of the crew (e.g., due to yellow fever), collisions, running aground, or even being seized by pirates, the enemy, or revolutionaries. 
even modest transaction costs. However, once the ship suffers some calamity necessitating rescue, there may be insufficient time to negotiate with a potential rescuer, that is, another ship that has chanced on the scene.

Consistently with this analysis, a claim for a salvage award is normally disallowed where the rescue was made pursuant to a pre-existing contractual relationship. Thus, the crew of the ship in distress or a tug under a towage contract is generally not entitled to salvage awards. However, in "extraordinary circumstances" the crew or tug is entitled to claim a salvage award. "Extraordinary circumstances" imply that the services provided were not bargained for, either explicitly or implicity, and thus were not compensated under the terms of the original contract. Failure to make awards in these circumstances would either reduce the Incentive for parties to provide valuable services or impose on the parties higher contract-information costs by forcing them to negotiate ex ante over low-probability events.

If the contract was first entered into at the time the ship was endangered, the presumption that it should be enforced fails. The rescuer may well have extracted extortionate terms from the victim, or, less obviously, the latter may have extracted unduly favorable terms. Both possibilities arise because, as mentioned earlier, the situation is one of bilateral monopoly. Since, as was shown in Part I, the enforcement of rescue contracts containing either extortionate or unduly favorable terms would lead to an inefficient allocation of safety and/or rescue resources, we would predict, and we find, that the courts will often set aside contracts not entered into at the time of peril and impose a noncontractual 
salvage award. 39

As to the size of the salvage award, we note first that the award is not limited to the salvor's expenses in rescuing the property in question (what is sometimes called the "quantum meruit" approach). This is economically correct. Since the probability of successful salvage is less than one and salvage awards are contingent on success (for reasons to be examined shortly), the award must be a multiple of the salvor's costs to be compensatory.

The factors that determine the amount of the salvage award are listed in Kennedy's salvage treatise as follows. 40

A. As regards the salved property:

(1) The degree of danger, if any, to human life.

(2) The degree of danger to the property.

(3) The value of the property as salved.

39. See Gilmore \& Black, supra note 37 at $578-81$, who give an alternative interpretation based on "fairness." Observe that our analysis justifies setting aside a rescue contract on the ground that the price is too low, as well as that it is too high; and this is done by the courts. It might appear that in a setting of bilateral monopoly rather than monopoly or monopsony, the expected price of rescue--which is, after all, the price relevant to fïms' decisions concerning investments in safety and rescue inputs--might be the same as the competitive price. However, the fact that price under bilateral monopoly will fall somewhere in between the monopoly and the monopsony prices does not imply that it will coincide with the competitive price, which is simply one point in that range.

There is the further point, noted by Gilmore \& Black at 381, that an agreement made after the danger has passed, for example an agreement to refloat the ship or salvage its cargo, is generally enforceable as written. Now competition is more likely, so on our interpretation efficiency is more likely to be promoted by enforcing these contracts.

40. Kennedy's, supra note 37 at 174. Although a British treatise, Kennedy's is frequently cited and its rules followed in American salvage cases. A similar list of the factors determining the amount of the salvage award in America appears in The Blackwell, 77 U.S. (10 Wall.) 1 (1869). We prefer the Kennedy's enumeration because of its greater specificity. 
B. As regards the salvors:

(1) The degree of danger, if any, to human life.

(2) The salvors' (a) classification, (b) skill and

(c) conduct.

(3) The degree of danger, if any, to property employed in the salvage service and its value.

(4) The (a) time occupied and (b) work done in the performance of the salvage service.

(5) Responsibilities incurred in the performance of the salvage service, such, e.g., as risk to the insurance, and liability of passengers or freighters through deviation or delay.

(6) Loss or expense incurred in the performance of the salvage service, such, e.g., as detention, loss of profitable trade, repair of damage caused to ship, boats, or gear, fuel consumed, etc.

This list is consistent with our hypothesis that the purpose of salvage awards is to provide incentives for efficient resource allocation. Each of the factors enumerated by Kennedy's provides relevant information for a legal system endeavoring to reconstruct the salvage contract that would have been negotiated ex ante if a competitive market transaction had been feasible. ${ }^{41}$

41. In a forthcoming paper, we show that the actual awards in salvage cases, and not just the legal principles, are consistent with the economic model. 
Factors $B(2),(4),(5)$, and (6) can be interpreted as attempts to estimate the aggregate market value (and hence full opportunity cost) of the inputs utilized in the rescue. Specifically, $B(2 b),(4 a)$, and $(4 b)$ are necessary to estimate the total quantity of quality-adjusted inputs-(4a) the total time and (4b) and (2b) the quality-adjusted inputs per unit of time--while the market value of each quality-adjusted input can be approximated from $(2 a),(2 b),(5)$, and (6). A complete measure of the alternative market value of inputs devoted to salvage must, and under (6) does, include repair costs (and in some instances has included depreciation due to damage to the rescuer's vessel), and opportunity costs (lost profits and other costs of delay). Since opportunity costs are likely to be substantial to salvors who are carrying cargo and passengers, failure to permit recovery of these costs could have serious adverse consequences on an important class of rescues.

Of further interest is $\mathrm{B}(2 \mathrm{a})$, which is used to differentiate ships and tugs that are built and maintained exclusively for salvage purposes from the nonspecialist (often the chance rescuer). It is well established that the professional salvor is entitled to more liberal compensation than the amateur. 42 Since perils arise relatively infrequently, the professional salvor (like a city's fire department) is idle much of the time. To encourage the creation of a class of professional salvors, the compensation awarded them for rescues must be sufficient to cover the costs of maintaining stand-by capacity. This capacity is costly but consider the alternative: at the time a ship was in distress, resources employed in other activities

42. See Kennedy's, supra note 37 at 168-73, and Gilmore \& Black, supra note 37 at 544 . 
would have to be mobilized since no stand-by capacity would be available, and the delay might defeat a successful rescue.

Misconduct by the salvor in the course of the rescue $(B(2 c))$, which includes preventing a more efficient rescuer (another vessel or the crew of the ship in danger) from rendering salvage services, or displacing without reasonable cause one already engaged in salvage services, will lead to a forfeiture or reduction in the salvage award. This discourages the inefficient rescuer--the rescuer who would have been underpriced (on a quality-adjusted basis) and eventually excluded in a competitive market.

Danger to the rescuer's life and property $(B(1)$ and (3)), a factor that will generate a larger award, is easily incorporated into the competitive model in Fart $I$ by a slight modification of the rescuer's cost function. 43 With this adjustment, the expected marginal costs of providing rescue inputs become a positive function of the degree of danger faced by the rescuer, and the zero expected profit equilibrium would require an upward adjustment in the rescuer's contingent fee.

43. Write the rescuer's cost function as

$$
\overline{\mathrm{C}}=\left(1-\mathrm{p}^{\mathrm{a}}\right) \mathrm{C}(\mathrm{y})+\mathrm{p}^{\mathrm{a}} \mathrm{kC}(\mathrm{y})
$$

where $\mathrm{p}^{\mathrm{a}}$ is the probability of an adverse outcome (death or property loss) to the rescuer, in which case his costs would be $k(k>1)$ times the costs of a non-adverse outcome. Expected marginal costs $\bar{C}\left(=C_{y}(1+p(k-1))\right)$ are greater than $C_{y}$ and hence $p^{r} v$, the expected compensation per unit of $y$, must be greater in the competitive equilibrium. Note that the rescuer may receive a lower total award because the greater expected marginal costs would also have induced the victim to purchase fewer inputs of $y$ if a competitive market were feasible. This contingency, however, is taken into account by the rules attempting to estimate the quantity of inputs. In effect, factors $B(1)$ and (2) represent the partial effect of greater danger to the rescuer, holding rescue inputs constant. 
The set of factors listed under $A$ in the Kennedy's list (i.e., those related to the victim's potential loss) include, first, the degree of danger to the victim's life and property. Our competitive rescue model requires that the greater the danger is, and hence the lower the probability of a successful rescue, the greater must be the aggregate compensation to the rescuer, holding constant the level of rescue inputs, assuming that compensation is paid only if the rescue attempt succeeds. Thus, to make the rescuer's compensation a positive function of the degree of danger is consistent with efficiency considerations.

$A(3)$ makes the award a positive function of the value of the property saved. The economic basis of this factor is superficially unclear, The value of the property saved is a measure of the victim's benefit from the successful salvage operation, but in a competitive market price equals marginal cost rather than the value to the buyer, which will exceed marginal cost for all but the marginal buyer. It might appear that "fairness" would explain the emphasis on the value saved but systems of price discrimination--i.e., of making price vary in accordance with value rather than cost--are not generally applauded as fair. 44

A better explanation may lie in the information that the value of the property saved provides for estimating the level of inputs that would be devoted to the rescue in a competitive market. The law's attempts to

44. It is therefore curious that Gilmore \& Black should take for granted the appropriateness of basing a salvage award on the value of the property saved but describe the obviously economic aspects of the salvage-award determination, discussed above, as the "moral aspects" of the award. Gilmore \& Black, supra note 37 at 562 . 
monitor the rescuer's inputs directly are bound to be imperfect. Since the optimal purchase of inputs in our model (equation (9)) is positively related to the value of the property saved, a court can utilize the latter to approximate the victim's demand for rescue inputs if transactions were feasible, and by doing so can encourage rescuers to provide the socially desirable quantity of rescue inputs. 45

A related rule limits salvage awards to cases of successful rescue; no award is made if the salvage operation, however skillfully performed, fails to save anything. By limiting salvage awards to successful rescues, the number of legal proceedings may be cut down, 46 while the courts can, by adjusting the award, compensate the salvors for their unsuccessful attempts. Also, it is difficult in a legal proceeding to estimate the degree of effort and energy of the rescuer. If payment were not conditional on success, the rescuer would have a greater incentive to reduce his effort and energy for a given quantity of rescue inputs. Just as the choice between piece-rate and fixed hourly wage methods of compensation depends on the costs of metering value of output relative to those of metering input effort, 47 so in rescues at sea, where the award is made after the event, the costs of monitoring effort and energy are obviously high, and here the

45. A final check on the salvage award is the established principle that it cannot exceed the value of property saved. This rule makes economic sense, since it is never efficient to spend $\$ 2$ to save (with a probability of less than one!) only $\$ 1$.

46. We say "may be" because the rule may generate litigation over the meaning of succusseful rescue.

47. See for example, Armen A. Alchian \& Harold Demsetz, Production, Information Costs, and Economic Organizations, 62 Am. Econ. Rev. 777 (1972). 
cost advantage is likely to lie with monitoring the output of which success is a crucial ingredient.

Another limitation on salvage awards is that an award for saving lives will be made only when property is also saved. This is traditionally explained by reference to the costs of collecting an award where there is no property saved to constitute a fund out of which to pay it. An additional element may be altruism. The model developed in Part I suggests that altruism is more likely to generate rescue effort the greater the disparity between the value of the thing saved and the cost of saving it. Lives at sea are not only extremely valuable (as elsewhere) but usually can be saved at lower cost than the ship itself or its cargo. Hence altruism may provide an efficient level of rescues in the pure life-salvage situation notwithstanding the competitive constraints that limit altruism by professionals. However, where both property and life are saved, it becomes vital to reward the salvor for the lives as well as property saved because saving a life may require the salvor to forgo saving some of the property. To deny a reward for life salvage in these circumstances would be to increase, perhaps dangerously, the opportunity costs of altruistic life saving. 48

48. The underlying principle was clearly recognized in a case which extended it to permit an award for pure life salvage where two salvors rescued a ship and its passengers and crew, and all the lives were saved by one of the salvors and all the property by the other. To deny an award for pure life salvage in such a case would tempt salvors to "gratify their avarice at the expense of their feelings of humanity." The Mulhnuse, 17 F. Cas. 962 (S.D. Fla. 1859) (No. 9,910). If, however, the ship had sunk before salvage efforts were commenced, and no property was saved, this temptation would not exist and a pure life salvage award would therefore be refused. See, for example, Chicago S.S. Co. v. The Eastland, 262 Fed. 535 (D. IIl. 1919).

The principle of only rewarding the salvor for saving lives if property is also saved may produce the following sequence of behavior that is difficult 
2. Abandoned Property at Sea. Two senses of "abandonment" must be distinguished. In the first, the members of the crew abandon ship, leaving it a derelict, because there is nothing further they can do to save it or because the danger to their own lives from remaining is too great. The ordinary rules of salvage apply to abandonment in this sense. Sometimes, however, the ship is abandoned by its owner--i.e., in a legal rather than merely physical sense. The rescuer of abandoned property in this sense is known as a finder rather than a salvor and his rights are governed by a distinct set of rules. It is these rules that govern, for example, most searches for sunken treasure.

Abandonment in the sense of relinquishment of property rights can be given a precise economic meaning that corresponds to the judicial results under both maritime and common law: property is abandoned where either (I) the owner has relinquished the property voluntarily because its expected value to him has become zero or negative, or (2) the owner's identity has become so obscure by passage of time or other circumstances that the costs of ascertaining it would be prohibitive. The general rule in such cases is to give the finder the title to the abandoned property. Although this is the obvious alternative to awarding salvage, given the absence of an owners to retake the property itself, it is likely to attract excessive

\footnotetext{
48 continued to reconcile with efficiency: the rescuer confronted by the possibility of simultaneously saving both property and lives will allocate his rescue resources initially to saving property and then to lives since the reverse sequence will result in no reward if the property is lost while the lives are being saved.
} 
resources into searching for abandoned vessels. ${ }^{49}$ The problem is even more serious here than in the salvage case. In the typical case of abandoned property the true social value of the finding is not the entire value of the property found but the (much smaller) benefit of recovering the property before the next finder who would have come along. Giving the finder the entire property value is analogous to giving a patent right equal to a very large fraction of the present worth of the patented discovery as a reward for the patentee's having made the discovery a week, say, before it would have been made by someone else.

In these circumstances, it comes as no surprise that the rule in England and in a minority of U.S. states is that abandoned property escheats to the state subject to a salvage claim by the finder. ${ }^{50}$ This would seem the more efficient rule, ${ }^{51}$ and it is a puzzle to us why it is not universal.

3. General Average. The rule of general average comes into play when part of the ship or cargo is voluntarily destroyed or thrown overboard to preserve the remainder of the ship and cargo at the time of a common peril at sea. If, for example, a ship has run aground and is in

49. See analysis in Part I. Note, however that another objection to giving the rescuer the entire value of the thing rescued is not present in the abandonment case: that it would attract excessive resources into prevention of perils by the owners. But see note 51 infra.

50. See John J. Kenny \& Ronald R. Hrusoff, The Ownership of the Treasure of the Sea, $9 \mathrm{Wm}$. \& Mary L. Rev. 383 (1967).

51. Assuming, of course, that the state does not invest its own resources (as would a private enterprise in its position) in increasing the likelihood of finding abandoned property. At least the state is not constrained, as would be a private enterprise, to follow this, the profit-maximizing course. 
danger of sinking, the total loss of ship and cargo may be avoided by jettisoning some cargo and rigging, which will lighten the ship and enable it to break free from the ground. In effect, the goods jettisoned are performing a rescue service. The rule of general average distributes the losses incurred among the owners of cargo and the shipowner in proportion to their stakes in the venture.

This rule, which is part of the admiralty law of most nations, has been colorfully described as "a perfect example of the peculiar communism to which seafaring men are brought in extremities. What is given, or sacrificed in time of danger, for the sake of all, is to be replaced by a general contribution on the part of all who have been thereby brought to safety." 52 Although this description suggests that general average has only distributive consequences, we shall show that it has important efficiency properties as well. 53

We first rank the cargo and parts of the ship that can be jettisoned in ascending order of value per pound, where $L$ and $x$ denote respectively the loss and the number of units (pounds) jettisoned, as in

$$
L=L(x)
$$

By definition of the ranking of $x$, the marginal loss from increasing $x$ is positive $\left(L_{x}>0\right)$ and increasing $\left(L_{x x}>0\right)$. The total value of the ship and cargo equals $L_{0}=V+\hat{L}$ where $V$ is the value of ship and cargo

52. Lowndes \& Rudolf, General Average 3 (Sth ed. 1964).

53. As independently suggested in Charles 0. Gregory, Harry Kalven, Jr., \& Richard A. Epstein, Cases and Materials on Torts 36 (3d ed. 1977). 
that cannot be jettisoned (if the ship is to remain afloat) and $\hat{\mathrm{L}}$ is the maximum loss of cargo and equipment jettisoned (i.e., $\hat{L} \geq L(x)$ for all $x$ ). Thus, $L_{0}$ is the potential loss if the ship and cargo are totally destroyed and no salvage is possible. The expected loss from the peril is then

$$
\overline{\mathrm{L}}=\left(1-\mathrm{p}^{\mathrm{r}}\right) \mathrm{L}_{0}+\mathrm{p}^{\mathrm{r}} \mathrm{L}
$$

where $p^{r}$ is the probability of rescue $\left(p_{x}^{r}>0\right.$ and $\left.p_{x x}^{r}<0\right)$. Assuming all utility functions are linear in income, $\overline{\mathrm{L}}$ is minimized and utility maximized when a level of $x$ equal to $x^{*}$ is selected such that

$$
-p_{x}^{r}\left(L_{o}-L\right)+p^{r} L_{x}=0
$$

or when the expected marginal returns from jettisoning $x\left(=p_{x}^{r}\left(L_{0}-L\right)\right)$ equals the expected marginal costs $\left(=p^{r} L_{x}\right)$.

How might $x^{*}$ be produced? Assume initially that transactions costs are zero, enabling all parties to the venture to negotiate costlessly. At the time the ship is aground and in peril, owners would bid for cargo and equipment to be jettisoned from other owners--in effect, bidding for rescue services would take place. (To complicate matters, there are owners on both sides of the market--i.e., at some prices they would offer their goods for rescue and at lower prices they would withdraw their supply offers and become bidders.) The results of the negotiations would have to be communicated immediately to the master of the ship who would then act to supply the desired level $x^{*}$ of rescue services.

In fact, at the time the ship is in peril and speedy action is critical, the costs of negotiating an agreement among the various parties are prohibitively high. The legal system has developed an ingenious and elegant rule, which has survived for several thousand years, the rule of general average, which provides incentives to accomplish precisely what a competitive market in rescue would achieve if transaction costs were zero. The general average assures 
(a) that for any given quantity of $x$, the goods jettisoned are the least valued (i.e., the goods jettisoned are ranked as in $L(x))$, and

(b) that the quantity of goods jettisoned equals $x^{*}$.

The general-average principle requires all owners to share in the loss $(L)$ in proportion to their share in the total value $\left(L_{0}\right)$ of the ship and cargo. Since the master of the ship is in the best position both to assess the peril and evaluate the most efficient rescue method, he is given the authority to determine which goods are to be jettisoned. No negotiation is required. With regard to (a) above, each owner's loss for a given quantity of $x$ will be minimized by selecting the lowest-valued (per lb.) goods to jettison. Thus, the master will have an incentive to use the least costly rescue procedure, providing he acts as the agent of any of the owners. Since each party shares in the loss, including the party whose goods are jettisoned, general average discourages owners from attempting to influence (if this were possible, via an arrangement with the master) which cargo and equipment are jettisoned. 54 That is, if full compensation were the rule, each owner would clearly prefer to have his goods jettisoned, whereas if no compensation were forthcoming each owner would prefer to have someone else's goods thrown overboard. As for condition (b), assume there are $n$ owners in the joint rescue venture. Let $l_{i}$ equal the value of goods lost to the ith owner if the ship sinks, $s_{i}$ his share in this loss $\left(s_{i}=\ell_{i} / L_{0}\right)$, and $k_{i} s_{i}$ his share in the losses of cargo and equipment jettisoned where $k \geq 0$. Note that

54. This was an especially serious problem in an earlier era when some merchants travelled on the ship with their cargo. 
$\operatorname{both} \sum_{1}^{n} s_{i}=1$ and $\sum_{l}^{n} k_{i} s_{i}=1$. The general average rules set $k_{i}=1$ for all $i$ so that each owner's share in $L(x)$ equals $s_{i}$. Can we derive this rule from an efficiency criterion? Assume that the master acts as the agent of any owner $i$. That owner would attempt to minimize his expected loss $\ell_{i}$ which equals

$$
\bar{l}_{i}=\left(1-p^{r}\right) \ell_{i}+p^{r} k_{i} s_{i} L .
$$

Minimizing (18) with respect to $x$ and noting that $L_{0} s_{i}=l_{i}$ yields

$$
-\mathrm{p}_{\mathrm{x}}^{\mathrm{r}}\left(\mathrm{L}_{\mathrm{o}} / \mathrm{k}_{\mathrm{i}}-\mathrm{L}\right)+\mathrm{p}^{\mathrm{r}_{\mathrm{x}}}=0 \text {. }
$$

Comparing (19) with the conditions for minimization of the aggregate expected loss in equation (17), we observe that as $k_{i}>1$ we allocate either less or more than the optimal amount of cargo and equipment to rescue. Only in the special case of $k_{i}=1$, which is the general-average rule, do we get the opcimal investment of resources in rescue. 55

B. Land Analogues to the Admiralty Rescue Doctrines

1. Agency of Necessity. In one of the examples discussed in Part I, that of the roof repair undertaken when the owners were abroad and could not be reached in time, the courts recognize a right to compensation under

55. General average is not the only possible method of minimizing aggregate expected losses in the situations in which it is applied. For example, were the shipowner to insure the losses of the other owners in exchange for higher freight charges, the former would have the correct incentive to minimize the aggregate expected loss. There are several possible explanations for the persistence and survival of the general average rule instead of shipowner strict liability. General average may be a method of diversifying risk among the various owners (which was ruled out in our analysis by the assumption of linear utility functions). It may function as an "optimal" deductible when insurance is not "fair." (Note that general average contributions tend to be a small fraction of the value of each owner's goods.) Since rescue operations are rare, a large number of ex ante transactions (that $i s$, the payment of insurance premiums) is avoided by the implicit selfinsurance scheme of general average. 
a doctrine called in England "agency of necessity." 56 The essential elements of the doctrine are (1) a pre-existing voluntary relationship between the owner and the agent and (2) an emergency preventing express negotiation over the services to be rendered. The doctrine seems a straightforward application of the theory of professional rescue developed in Part I. It is an effort to encourage the agent to provide the level of rescue resources that would have been bargained for if a voluntary exchange had been feasible. Because the rescuer is a professional, and because the cases in which the doctrine is invoked do not involve the sorts of perils that create dramatic wealth disparities between the parties, the motivation for altruistic rescue is weak. The emergency precludes a voluntary negotiation, while the existence of a pre-existing relationship between parties makes it relatively easy for the court to write a contract ex post. 57

2. The Rights of Land "Salvors." We now examine the circumstances where, as under the maritime law of salvage, a land rescuer can claim a reward under common law princlples where there is no pre-existing contractual relationship between rescuer and victim. 58

56. See Robert Goff \& Gareth Jones, supra note 5, at 231-35. Similar results are reached under American law but without use of the term. See, for example, Berry v. Barbour, 279 P.2d 335 (0kla. 1954)(the roof repair case); John P. Dawson \& George E. Palmer, Cases on Restitution 52 (2d ed. 1969); Frederic Campbell Woodward, The Law of Quasi Contracts 308-35 (1913).

57. There is an analogy here to that part of the law of general average in marltime rescues that imposes a duty on the master to jettison cargo or take other steps, not prescribed in the contract with the shippers, to avert a larger loss. The absence from land law of the distinctive loss allocation procedure of general average may reflect simply the infrequency of land disasters in which some of the goods have to be destroyed to save the rest. The closest land analogy to jettison, perhaps, is where, in a fire case, one person's property must be allowed to burn to save the rest. Occasionally it has been suggested that a principle analogous to the maritime law of general average would be applied in such a case. See Mayor of New York v. Lord, 18 Wend. (N.Y.) 126 (1837); Bishop \& Parsons v. Mayor of Macon, 7 Ga. 200 (1849).

58. The principal legal doctrines are summarized in Restatement of Restitution ch. 5, and Frederic Campbell Woodward, supra note 56, at ch. XIV. 
(a) Life Salvage. A common law right to compensation for rescue is most clearly established in the case where assistance is rendered to someone incapable of contracting because of either emergency or incapacity, as where a physician renders medical assistance to a person he finds lying unconscious in the street. The rescuer must, in the language of the Restatement of Restitution, establish a presumption that where a professional (e.g., physician) is the rescuer he does intend to charge and is entitled to compensation equal to his usual fee for the type of service rendered to the rescued person. Conversely, the nonprofessional rescuer is presumed not to intend to charge. 60

This distinction may have an economic rationale. ${ }^{61}$ The physician is a professional. Both the opportunity cost of his time and the amount of time he provides in rendering medical assistance are likely to be greater than those of the passerby who, noticing a person lying injured in the street, must decide whether to summon assistance. The greater cost to the physician of effecting rescue reduces the likelihood that altruism alone would prompt him to do so. At the same time, the costs to the legal system of determining an appropriate award are lower in the professional's case: the award can virtually be read off the physician's fee schedule, whereas the nonprofessional rescuer by definition does not sell equivalent services in a market. One difference between common law and maritime principles is that while the maritime salvor is rewarded only if the salvage is successful, the

60. The case law appears to go beyond the Restatement and make the presumption of no intent to charge irrebuttable, with the result that the nonprofessional rescuer is never entitled to a monetary reward. See id at 314 .

61. As implicitly recognized in John P. Dawson, Negotiorum Gestio: The Altruistic Intermeddler, 74 Harv. L. Rev. 817, 1073, 1085, 1126 (1961). 
physician (or other professional rescuer on land) is entitled to his normal fee regardless of success. However, medical treatment is more standardized than maritime salvage technique and therefore more readily evaluated. This, combined with the difficulty in many cases of evaluating the contribution of the physician's services to the patient's recovery, is no doubt why physicians generally charge for services rendered rather than the results obtained; consistently with its fundamental (economic) purpose of simulating the market, rescue law follows this pattern. 62

The principal difference between the common law and the maritime law of life salvage is that even a professional rescuer of lives at sea is not entitled to compensation unless property is also saved, whereas the professional rescuer of lives on land (typically a physician) is entitled to

62. A question has sometimes arisen whether the proper fee to award to the physician in a rescue case is his standard fee or the standard fee of physicians in his locality. The courts correctly hold that it is the former. The higher fee presumably reflects a higher quality of services rendered, but even if it does not, it would be a mistake to give the physician less for it would induce him to substitute away from providing service in emergencies.

The courts have divided over a related question--whether, if the physician regularly varies his charges according to the income of the patient (that is, price discriminates), he should be permitted to claim a higher fee in a rescue case where it turns out that the person he treated was affluent. Compare Cotnam v. Wisdom, 83 Ark. 601, 104 S.W. 164 (1907), with Matheson v. Smiley, 40 Man. 247, [1932] 2 D.L.R. 787. The physician in his normal practice "sizes up" the patient and charges according to an estimate of the patient's income, but he does not make a thorough investigation to find out what the income actually is. In the emergency case, where there is no regular physician-patient relationship, the physician might after the fact undertake a rather minute investigation of the patient's financial circumstances to enable him to discriminate more precisely than he normally does. This is an argument against permitting discrimination in the rescue case. The more common argument that discrimination is morally or economically objectionable is simply irrelevant in this setting since the purpose of the rescue award should be to simulate rather than reform the practices prevailing in the professional's regular market. To use rescue doctrine to change the medical fee system vould be quixotic. 
compensation regardless of whether property is also saved. This difference is difficult to explain on economic grounds. It may be related to the high probability that multiple lives will be at stake in a sea emergency, in which event the gains from, and hence demand for, altruistic rescue may be high even though the potential rescuers are professionals.

There is an exception to the refusal to compensate the land rescuer who is not a professional: if the rescuer is injured and the peril to which he responded was due to negligence. ${ }^{63}$ The easiest case is where the rescued person was endangered by the negligence of a third party and the infured rescuer seeks damages from that party. We showed in our model of professional rescue that if the sum of the expected costs of the accident victim and of the rescuer is less than the expected costs of the accident had no rescue attempt been made, a rational tortfeasor would gladly have promised to reimburse the rescuer for his injury if, by so doing, the tortfeasor could have induced him to make the rescue attempt. In imposing liability in such cases the courts are simply enforcing the (hypothetical) contract that the tortfeasor and the rescuer would have made had time permitted.

Consistently with this analysis, the rescuer is not permitted to recover damages from the tortfeasor if the danger of the rescue attempt was disproportionate to the expected loss from the accident. 64 And if the emergency was caused by the victim's own negligence, then it is the victim who would (hypothetically) contract with the rescuer and efficiency requires placing liability for the rescuer's injury on the victim, which is what the courts do. 65

63. See, for example, Wagner v. International Ry. Co., 232 N.Y. 176, 133 N.E. 437 (1921).

64. As in Berg v. Great Northern Ry. Co., 70 Minn. 272, 73 N.W. 648 (1897). See Annot., 42 A.L.R.2d 494 (1955).

65. See Annot., 4 A.L.R.3d 558 (1965). 
A superficially attractive argument for changing the law to permit the rescuer to obtain compensation for infury sustained in the course of a rescue, regardless of any negligence on the part of the victim or some third party, is that a rescue which injures the rescuer is costly and our model of altruism predicts that rescue attempts will be less frequent the greater the costs of rescue. But this argument confuses ex ante and ex post costs. If the probability of a serious injury to the rescuer is slight ex ante, then the expected cost of rescue will not be substantially higher than if there were no danger, while if the probability of a serious injury to the rescuer is high ex ante, the net expected benefits from the rescue attempt are apt to be small or even negative. ${ }^{66}$ In neither case is there a substantial basis for seeking to alter the level of (altruistically induced) rescues by always giving the rescuer a right to compensation for his infury.

(b) Property Salvage. Although, contrary to the maritime law, the traditional common law rule is that the rescue of property, other than pursuant to a contract, does not entitled the rescuer to any compensation, 67 there is a question how firmly established this rule really is. There have

66. This suggests an economic basis for Professor Dawson's objections to the result in a German case where rescuer and victim both died in the rescue attempt and the rescuer's widow was allowed to recover a reward from the rescuee's widow. See John P. Dawson, supra note 61, at $1114,1127$.

67. See Bartholomew v. Jackson, 20 Johns. 28 (N.Y. 1822); Glenn v. Savage, 14 Ore. 567, 13 P. 442 (1887).

One exception to this rule is the British doctrine of "treasure trove." A treasure trove is a cache of gold, silver, coin or bullion hidden away under ground or in a building. While in America the finder has the right to possession against all but the true owner, in England the sovereign has title to treasure trove. Atty.-General v. Trustees of Br. Museum, [1903] $2 \mathrm{ch}$. 598. However, the finder is entitled to "20 percent from the antiquarian value of the coins or object, retained; or a sum of 10 percent from the value of all the objects discovered." Martin, Treasure Trove and the British Museum, 20 L.Q. Rev. 27, 39 (1904). 
been few cases, and the two leading ones ${ }^{68}$ are anomalous in that each involved a pre-existing contractual relationship between the parties. For example, in Bartholomew v. Jackson the plaintiff had been hired to burn stubble in the defendant's cornfield. When plaintiff discovered that defendant had failed to remove his wheat, which was in danger of burning from the fire in the cornfield, he saved the wheat. If the case arose todpy, it would probably be decided in plaintiff's favor under the doctrine, discussed earlier, of agency of necessity.

The most recent case we have found, Frost v. Ponca City, ${ }^{69}$ allowed the property salvor to recover his expenses despite the absence of any agency of necessity. Plaintiffs discovered valuable hydocarbons beneath their land and applied for a permit to drill. The defendant city refused the permit because of the danger of explosion from uncontrolled drilling, but later extracted and sold the hydrocarbons itself. The plaintiffs sued for the entire receipts of the city's sales. The court, relying on (while actually extending) a leading agency of necessity case, ${ }^{70}$ held that the city was entitled to keep a portion of the receipts to cover its drilling and marketing expenses. In effect, the city was allowed to recover its expenses of saving the plaintiff's property although there had never been a contractual relationship between the parties. This decision suggests that the common law may be moving away from its traditional refusal to recognize

68. See note 67 supra.

69. 541 P.2d 1321 (Okla. 1975).

70. Berry v. Barbour, 279 P.2d 335 (Okla. 1954). 
a right of property salvage on land.

Moreover, the vitality of that rule has long been sapped by a major exception to it, entitling the finder of lost property to compensation for his expenditures in preserving it. ${ }^{71}$ For example, in Chase v. Corcoran, ${ }^{72}$ plaintiff found defendant's boat adrift on a river and in danger of sinking. He brought the boat ashore, made necessary repairs, and stored the boat for almost two years until defendant claimed it. He was held entitled to recover his expenditures in repairing and storing the boat. Under the rationale of this case, the wheat in Bartholomew v. Jackson would have been regarded as lost or misplaced property found by the plaintiff and preserved by him, thus entitling him to a reward.

The common law's traditional reluctance to recognize property salvage rights may be related to the typically much smaller values involved in land than in sea rescue cases. As should be plain from our earlier discussion of the computation procedure used in maritime salvage cases, the costs of administering a system of salvage rights are considerable and cannot be justified where the things saved are of little value. This analysis is supported by another property salvage case in which compensation was awarded under common law, Vincent v. Lake Erie Transp. Co. ${ }^{73}$ The defendant lashed his ship to the plaintiff's dock to prevent it from being destroyed by a storm. Although the ship was saved, the plaintiff's dock was damaged in the process and the plaintiff was allowed to recover the damage. The result

71. However, only out-of-pocket expenses are compensated. See Kirk v. Smith, 48 Mont. 489, 138 P. 1088 (1914).

72. Chase v. Corcoran, 106 Mass. 286 (1871). See also Frederic Campbell Woodward, supra note 56, at 327-30.

73. Vincent v. Lake Erie Transp. Co., 109 Minn. 456, 124 N.W. 221 (1910). 
seems correct. The plaintiff was a commercial enterprise, lives were not at stake, and the ex ante costs of rescue were significant though much smaller than the benefits. 74

\section{(c) Nonaccident Cases. The cases discussed in the preceding two}

sections involve the resuce of lives or property imperiled by an accident, but these are by no means the only cases of "rescue." For example, if a person dies and it is infeasible to get in touch with his family in time, a stranger may bury the person and claim compensation from his estate. Similarly, in the period after a person dies intestate but before an administrator is appointed for the estate, one who renders a nondeferrable service to the estate ( $\underline{\mathrm{e} . \mathrm{g}}$., by providing food to the widow) can claim compensation from the estate. ${ }^{75}$ These cases represent straight forward applications of the basic economic principles of the professional rescue model developed in Part $I$.

Another class of cases involves the satisfaction by a third party of

74. As a detail, we note that in common law cases where the courts do recognize salvage rights, they have traditionally spoken of an "implied contract" between the parties. This usage has been sharply criticized as involving a fiction. See, for example, United Australia, Ltd. v. Barclays Bank, Ltd., [1941] A.C. 1, 23-29. Modern writers prefer to view the obligation as imposed in order to avoid the "unjust enrichment" of the victim at the expense of the salvor. See, for example, Robert Goff \& Gareth Jones, supra note 5, at 10-11. Yet the older term can be given a precise economic meaning: an implied contract is one the parties did not make but would have made had they had the opportunity to negotiate, because the circumstances made an exchange between them necessary to maximize value.

As a further refinement, one can distinguish between a contract "implied in fact" and one "implied in law." The former is a contractual agreement inferred from a previously existing contractual relationship between the parties, the latter an agreement fashioned by the court between parties who did not previously have such a relationship. The rule of general average illustrates the former, the right of a physician to reimbursement from the unconscious accident victim whom he finds in the street the latter.

75. See Frederic Campbell Woodward, supra note 56, at 319-20. 
either a statutory or a contractual obligation when the obligor has failed to act. The principal statutory obligation involved in the cases is the husband's duty to provide "necessaries" to his wife and children. A third party can satisfy a statutory obligation and obtain reimbursement from the obligor (the husband) whether or not the situation is one of emergency. But where the obligation is created merely by contract, there is a right to reimbursement only if there is an emergency (or, what amounts to the same thing economically, mental incapacity to contract). The difference in legal responses may reflect differences between the two cases as regards the (economic) consequences of the third party's failure to intervene. In the statutory-obligation case, if the husband fails to perform his obligation of support, responsibility for enforcement devolves on the state. Third-party intervention is here an inexpensive form of private enforcement and is encouraged by granting reimbursement. This point is especially compelling in the case--which appears to be the most common--where the breach is of the duty of child support. Since the child is often incapable of looking after his own interests, even to the extent of complaining to the authorities, effective public enforcement would be extremely difficult. In the contract case, however, the victim of the breach of contract can look after his own interests, and here the emergency rule identifies the one case in which high transaction costs preclude a bargained solution and justify unbargained assistance.

A difficult group of cases involves situations where, although the number of parties is small, usually only two, there are pronounced elements of bilateral monopoly. Some example are:

(1) A and B are joint tenants of a property. A makes improvements and seeks to charge B for a share of them. B refuses. Has A a legal claim against $B$ for reimbursement of a share of the expense? 
(2) A and B are second mortgagee and mortgagor, respectively. A pays the interest owed by $B$ to the first mortgagee in order to avoid a foreclosure which would wipe out A's, the junior creditor's, interest. Can A sue $B$ for the discharge of $B^{\prime}$ 's debt?

(3) A and B are adjacent landowners. Both are plagued by marshy soil conditions. A drains his land and in doing so unavoidably lowers the water table on $B^{\prime}$ 's land as well, to B's benefit; can A claim from B a share of the expense of drainage. ${ }^{\mathbb{6}}$

Example (2) brings out the sharp difference between this group of cases and those previously discussed. A in the example is seeking reimbursement for discharge of another's contractual obligation, even though no emergency precluded negotiations between A and B. However, earlier we suggested an economic rationale for judicial intervention in cases where the parties are bilateral monopolists, and we saw that the courts in admiralty cases do in fact intervene in such cases.

How does the common law deal with the problem? In case (1), joint tenancy, the improver's claim for restitution is denied. In case (2), discharge of another's debt to protect one's own interest, restitution is allowed. And in case (3), improvement by one landowner that benefits his neighbor, restitution is again denied. Although the pattern of the cases has been called "decidedly irregular," 77 it appears to be consistent. with the economics of the problem. Since a joint tenant has a right to the

76. For a good discussion of such cases see John P. Dawson, The SelfServing Intermeddler, 89 Harv. L. Rev. 1409 (1974).

77. Id. at 1418 . 
partition of jointly owned property, the usual effect, and apparently the purpose, of denying restitution for a joint tenant's improvements is to induce the partition of the property. ${ }^{78}$ This eliminates the problem of bilateral monopoly, at least in the typical case, because after partition an improvement by one of the former joint tenants will no longer confer an uncompensated benefit on the other.

In the debt case, the usual objection to the courts' writing contracts between parties who failed to agree on terms--that the courts cannot readily approximate the terms that would have been negotiated in a competitive market-is absent. The amount of the debt that is discharged, a sum certain, is a close approximation to the competitive price for the service rendered by the discharging party to the debtor. The costs of using the legal system in this case are low relative to those of a market dịtorted by biląteral monopoly .

The most difficult case is that of the neighboring landowners where an improvement by one must benefit the other. ${ }^{79}$ The choice between forcing the parties to bargain under conditions of bilateral monopoly and using the legal system to measure the benefit conferred on the nonagreeing landowners is a difficult one, so we are not surprised that the legal system should here opt for nonintervention.

3. Promises Supported by "Moral Obligation." Suppose that, a rescue having been effected but the rescuer injured, the grateful victim promises

78. Id. at 1423-27.

79. These include, however, joint-tenancy cases in which, even after partition, an improvement by one of the former joint tenants of his now wholly owned parcel would unavoidably increase the value of the parcel owned by the other former joint tenant. 
to reimburse the rescuer's medical expenses. He later reneges, the victim sues, and the question is whether there was a breach of contract. Since the consideration for the promise of reimbursement--the rescue--occurred prior to the promise of reimbursement, it does not fit the usual definition of consideration, i.e., something bargained for. Nonetheless the courts will enforce such a promise as supported by "moral obligation." 80 This is not an illuminating term: why should not every promise be viewed as resting on--or if need be creating--a moral obligation, and hence enforced?

One approach is to view the promise to the rescuer as an acknowledgement that the exchange of the rescue services for the promised sum was a valuemaximizing exchange. The objection to restitution in rescue cases--and it is not one to be dismissed lightly, though it is not always decisive--is that the courts should not try to write contracts for people who have failed to agree on terms; if the necessary terms are supplied by the rescue victim's promise, this objection disappears.

A different point also supports the same result. One purpose of the requirement of consideration in the law of contracts is evidentiary (which is why the requirement is not found in systems where oral contracts are generally not enforced). We do not usually expect people to make promises without consideration so we are suspicious when it is claimed that they have done so. But in some circumstances a unilateral promise is quite expectable, and the case where the rescuer has been injured in the course of a successful rescue is one: our economic model of altruism predicts that the dramatic reversal in wealth positions is likely to lead to a transfer

80. See, for example, Webb v. McGowin, 27 Ala. App. 86, 168 So. 196 (1935). 
from the rescued individual to the injured rescuer.

It may be difficult to see, however, how enforcement could materially affect the allocation of resources to rescue, since the promise is by definition not made to induce rescue (if it were, its enforceability would be beyond question). But there may be other benefits from enforcing such a promise. If, for example, A, having been rescued by $B$, promises to pay B $\$ 50$ a week for the rest of B's life, A presumably derives greater utility from the promise if the promise is legally enforceable. Indeed, if A were unable to make a binding promise in these circumstances, the full extent of his altruism could not be known until B died! A might therefore decide to buy an annuity for B that would have a much lower present value than the $\$ 50$ a week promise (perhaps because A does not have and cannot borrow the sum necessary to purchase an annuity of that size) in order to receive immediate recognition of his altruism. Since refusal to enforce even a gratuitous promise may reduce utility, one is not surprised to find that the evidentiary (administrative-cost) objection to enforcing such promises is not present, so, as in the rescue case, the courts will enforce them. ${ }^{81}$

\section{The Unilateral Contract. Another contract-law concept}

that encourages rescues notwithstanding the absence of a general common law counterpart to the maritime salvage doctrine is that of the "unilateral contract." The owner of lost property can post a reward and anybody who, knowing of it, complies with its terms is legally entitled to it. The posting of the reward is the "offer" and performance of its conditions the "acceptance"

81. See also Richard A. Posner, Gratuitous Promises in Economics and Law, $6 \mathrm{~J}$. Leg. Studies 411 (1977). 
which creates a legally binding contract. Because the potential finders of lost property will often be numerous and unidentified, there is no feasible way in which the owner could negotiate with each of them for the return of his property. The unilateral-contract approach enables voluntary transacting without actual negotiations with the potential transactors. This is a superior solution to giving the finder title to the lost property-which would overcome the transaction-cost problem but in doing so would create the kind of monopoly problem we discussed earlier in the maritime context.

Since the unilateral-contract doctrine enables the parties in the lostproperty situation in effect to write their own contract, the law need not intervene and write a contract for them prescribing the finder's reward. But it is difficult to see how this device could be used effectively in the context of endangered vessels. And even in the case of lost property on land, the unilateral-contract device may not be entirely adequate. In some cases, for example, the cost of communicating the terms of the offer to potential finders (who may be numerous and scattered) will be disproportionate to the value of the property lost. This is the economic basis of laws found in some states entitling the finder of lost property to claim a fixed reward (e.g., 10 percent of the value of the property found) from the owners, whether or not the owner has offered any reward. ${ }^{82}$ owners in general may benefit from such a law because the knowledge of the law will activate some finders to whom the terms of an offered reward could not be communicated at reasonable cost.

82. See, for example, Flood v. City National Bank of Clinton, 253 N.W. 509 (Ia. 1934); Annot., 95 A.L.R. 1176 (1935). 
Laws forbidding retention of lost property are consistent with the foregoing analysis; they prevent the property right from vesting in the finder, a result we said would be inefficient. However, a highly questionable--and generally rejected-- ${ }^{83}$ use of the laws compelling return of lost property has been to deny the finder the right to claim a reward offered by the owner. 84 The "reasoning" is that since the finder had to return the property under compulsion of law, the return is not consideration supporting the promise of a reward and the promise is therefore unenforceable. But the owner of the property, knowing of the law and gauging its effect, will adjust the reward according to his perception of its effectiveness. If he still offers a positive reward, this suggests that the resources devoted to enforcing the law are insufficient to induce the optimal level of finding.

5. Sea and Land Rescue Law Compared. Although both the maritime and land doctrines related to rescue or salvage reveal the stamp of economic thought, the maritime rules reflect a greater economic sophistication. Why--economically--might this be so?

1. Maritime commerce is the oldest of large-scale commercial activities and its technology has changed relatively little over a period of several millenia; assuming efficiency principles have survival value in law, ${ }^{85}$ there has been enough time for an efficient maritime law to evolve.

83. See, for example, Berthiaume v. Doe, 22 Cal. App. 78, 133 P. 515 (1913). 84. See Rheinhauer v. DeKrieges, 188 Misc. 747,67 N.Y.S. 2d 211 (N.Y. City Ct. 1946); Note, Rewards for the Return of Lost Property: Are They Void in New York?, 24 St. John's L. Rev. 287 (1950).

85. As argued in Paul H. Rubin, Why is the Common Law Efficient?, $6 \mathrm{~J}$. Leg. Studies 51 (1977), and George L. Priest, The Common Law Process and the Selection of Efficient Rules, 6 id. at 65. 
2. Law can be expected to follow economics most closely in areas of low transaction costs where, if legal doctrine is inefficient, the affected parties will contract around it. Although in particular rescueat-sea settings transaction costs are prohibitively high, there is often a background of voluntary transacting pushing the development of the law in an efficient direction. For example, while at the moment of crisis the owners of the cargo cannot feasibly negotiate whose cargo is to be jettisoned, thus necessitating a rule such as that of general average, were the rule an inefficient one the cargo owners would have a strong incentive to establish a different rule by contractual arrangements entered into before the voyage.

3. In international maritime commerce, there is no central authority to impose an inefficient rule on its subjects by virtue of having an effective monopoly of coercion. Thus the nation that adopts the most efficient admiralty rules will increase its share of international maritime commerce through a competitive process. 86 The situation is analogous to the competition among U.S. states to issue corporate charters, a competition which encourages efficient rules of corporation law to emerge. 87

4. The benefits of economically correct legal principles governing rescue at sea are greater than in the case of land rescue. The dense network

86. This depends of course on the extent to which the law of either the "flag state" or the forum state is followed in maritime cases, which in turn depends on the highly complicated rules of international conflict of laws. It appears that some deference at least is paid to the laws of these states, so that any nation desiring the commercial cdvantages accruing from either status would have an incentive to adopt efficient rules. This incentive is reinforced by the possibility of retaliation by foreign nations against a nation that adopted rules which inhibited international commerce.

87. See Richard A. Posner, Economic Analysis of Law 306-07 (2d ed. 1977); Ralph K. Winter, Jr., State Law, Shareholder Protection and the Theory of the Corporation, $6 \mathrm{~J}$. Leg. Studies 251 (1977). 
of public rescue services on land--police, firemen, the National Guard, etc.-reduces not only the scope of efficient private rescue but the cost of those private rescues that are efficient--often to that of a telephone call. 88 Thus, the social demand for private rescues is small, and because of the low cost to rescuers of satisfying that demand altruism can probably be relied upon to motivate them. In the maritime case, notwithstanding the activities of the Coast Guard and navy, most rescue activity is private and its costs too great to rely on altruism to motivate 1t. One should therefore not be surprised that the intricate and economically sophisticated rules of the maritime law concerning rescue are not duplicated in the corresponding land law; it would not pay to achieve the same level of economic sophistication there.

\section{The Good Samaritan (Liability for Nonrescue) Question}

The common law has traditionally refused to impose liability for failure to assist a stranger in distress, no matter how. low the costs of assistance would be or how great its benefits. 89 It has been argued that the absence of a liability rule is inefficient and contradicts the positive economic theory of the common law. 90 In fact, as our analysis will show, liability may be less efficient than nonliability.

1. Effect on Rescue Activity. Let people who fail to undertake cost-

88. Of course, the level of public rescue services may not be optimal. If it were excessive, conceivably a reward system might be justified as reducing the demands placed on the overextended public system. We assume, however, that the judges in elaborating and applying rescue law do not attempt to evaluate the optimality of the public rescue system or otherwise to achieve a global optimum; they simply lack the requisite information.

89. See, for example, Yania v. Begin, 397 Pa. 316, 155 A. 2d 343 (1959); The Good Samaritan and the Law (James M. Ratcliffe ed. 1966).

90. See Richard A. Epstein, supra note 3, at 189. 
justified rescue efforts be liable for the losses of the victim. Put differently, if the rescuer's inputs are less than $y^{*}$ (the quantity that would minimize the expected losses from the hazard), he is liable for the victim's loss, $L_{\circ} \cdot 91$ since the liability rule (subject to qualifications discussed shortly) will not alter the behavior of rescuers whose altruism is sufficiently strong to generate a level of rescue inputs to $\mathrm{y}^{*}$ or greater, we focus on the class of hazards where altruism yields a level of inputs less than $\mathrm{y}^{*}$.

The potential rescuer will then face a choice between the following alternatives:

(1) a legally imposed penalty of $\mathrm{L}_{0}$ if the victim is injured, and rescue expenditures of $\mathrm{C}\left(\mathrm{y}_{0}\right)$, where $0 \leq \mathrm{y}_{0}<\mathrm{y}^{*}$; or

(2) no liability if the victim is injured, but rescue expenditures of $\mathrm{C}\left(\mathrm{y}^{*}\right)$.

Assuming initially that the liability rule is administered without error, one can show that $\mathrm{y}^{*}$ (alternative (2)) would be chosen because any level of $\mathrm{y}<\mathrm{y}^{*}$ would yield a lower utility. 92 Thus, liability yields, as a

91. This definition of liability is equivalent to the formal definition of negligence that has been utilized in the economic analysis of torts. See John P. Brown, Toward an Economic Theory of Liability, $2 \mathrm{~J}$. Leg. Studies 323 (1973); Peter A. Diamond, Single Activity Accidents, 3 id. 107 (1974).

92. The rescuer's utility if he chooses alternative (1) is

$$
U^{r}=g\left(W^{r}-C\left(y_{0}\right)-\left(1-p^{r}\right) L_{0}\right)+h\left(W^{v}-\left(1-p^{r}\right) L_{0}\right)
$$

where $\mathrm{y}_{0}<\mathrm{y}^{*}$. But when $\left.\mathrm{y}=\mathrm{y}^{*}, \mathrm{C}(\mathrm{y})+1-\mathrm{p}^{\mathrm{r}}\right) \mathrm{L}_{0}$ is minimized. Therefore, $g\left(W^{r}-C\left(y^{*}\right)-\left(1-p^{r}\right) L_{0}>g\left(W^{r}-C\left(y_{0}\right)-\left(1-p^{r}\right) L_{0}\right)\right.$

and a fortiori the no liability alternative.

$$
\mathrm{g}\left(\mathrm{W}^{\mathrm{r}}-\mathrm{C}\left(\mathrm{y}^{*}\right)\right)>\mathrm{g}\left(\mathrm{W}^{\mathrm{r}}-\mathrm{C}\left(\mathrm{y}_{\mathrm{o}}\right)-\left(1-\mathrm{p}^{\mathrm{r}}\right) \mathrm{L}_{\mathrm{o}}\right) \text {. }
$$

Further, since $p^{r}$ is greater at $y^{*}$ than $y_{0}$, the utility from the victim's expected wealth $(h())$ is greater at $y^{*}$ than $y_{0}$. 
first approximation, the same level of rescue inputs as the compensation scheme in the model of altruism in Part I. 93 But imposition of liability for nonrescue has one attractive feature in comparison to compensation: no transfer payment need be calculated or made in most cases because the threat of liability should suffice to induce the cost justified level of expenditures on rescue. ${ }^{94} \mathrm{~A}$ well functioning liability system would economize on the transaction costs that rescuers and victims would have to incur under a system of legally enforced compensation. However, this analysis overlooks the possibility that potential rescuers will avoid liability by substituting away from activities that give rise to rescue opportunities. Since the imposition of liability is equivalent to a tax on these activities (provided the inputs necessary to avoid liability ( $y^{*}$ ) are greater than the quantity that would be supplied by the rescuer in the absence of a liability rule), this will have the usual effect of inducing substitution away from the taxed activity.

Assume that activity $\mathrm{A}$ is hazardous, thus creating rescue opportunities and let the number of victims and potential rescuers in $A$ equal $v$ (initially assumed fixed at $v_{0}$ ) and $n^{a}$ respectively. No victims are present in the alternative activity $B$ and therefore no rescue opportunities exist for the $n^{b}$ persons entering B. ${ }^{95}$ Although $\mathrm{n}^{\text {a }}$ represents the set of potential rescuers, not all of these persons will encounter a victim and be called on to rescue. It seems reasonable to assume that the probability of a person's encountering

93. Compensation, however, would lead to additional expenditures on rescue in situations where $h^{\prime} / g^{\prime}$ was greater than one at $y^{*}$.

94. This is, incidentally, a highly relevant but neglected consideration in the comparison of subsidies and taxes as methods of cost internalization.

95. We assume that an individual is either a nonvictim or a victim but not a member of both classes. A more complicated model would allow an individual to be both a potential victim and a potential rescuer or nonvictim. 
a victim in $A$ is inversely related the ratio of potential rescuers to victims, as in $\theta=\theta\left(\mathrm{n}^{\mathrm{a}} / \mathrm{v}\right)$ where $\theta^{\prime}<0$. That is, the greater the number of potential rescuers in A relative to victims, the less likely it is that any particular potential rescuer will encounter a victim and be called on to rescue.

A potential rescuer will choose to enter activity A or B after the

where $U^{a}$ equals his pre-liability utility in $A, U^{b}$ his utility in $B$, and $\Delta U^{\mathrm{a}}$ the reduction in his utility in $\mathrm{A}$ due to the liability rule. It follows from (20) that given the distribution of $\Delta U^{a}$, the greater the substitutability between activities $A$ and $B$, the smaller will be the average difference between $U^{a}$ and $U^{b}$ for a group of potential rescuers, and the greater the proportion who switch from activity $A$ to $B$ in response to the imposition of liability. Similarly, given the degree of substitutability between the two activities, the greater the value of $\Delta \mathrm{U}^{\mathrm{a}}$ on average, the greater will be the shift from $A$ to $B$. $\Delta U^{\mathrm{a}}$, which equals

$$
\Delta \mathrm{U}^{\mathrm{a}}=\theta \int_{\mathrm{y}_{\mathrm{O}}}^{\mathrm{y}^{*}}\left(\mathrm{~g}^{\prime} \mathrm{C} \mathrm{y}^{-} \mathrm{h}^{\prime} \mathrm{p}_{\mathrm{y}^{\mathrm{r}} \mathrm{L}_{\mathrm{o}}}^{\mathrm{r}}\right) \mathrm{dy},
$$

will tend to be greater (a) the greater the likelihood that a rescuer will encounter a victim ( $\underline{\text { i.e. }}$, the greater $\theta$ ) and hence the more likely it is that he will be liable for failure to rescue, and (b) the greater the difference between the quantity of inputs necessary to avoid liability ( $\mathrm{y}^{*}$ ) and the quantity that would be supplied in the absence of a liability rule $\left(\mathrm{y}_{0}\right) .96$ The difference between $\mathrm{y}^{*}$ and $\mathrm{y}_{0}$, in turn, will be greater the 96. By definition $\Delta U^{a}=0$ for persons supplying rescue inputs in excess of $\mathrm{y}^{*}$ in the absence of a liability rule. 
lower the level of altruism. Also, the disutility of the liability tax to each individual remaining in activity $A$ will tend to be greater the smaller the number remaining (holding $v_{0}$ constant), because the likelihood will be greater that those remaining will encounter a victim and be called on to rescue ( $\underline{\text { i.e. }}, \theta^{\prime}<0$ ).

Our definition of the liability rule implied that there would be no effect on the behavior of "strong" altruists (‥e., people who would have provided rescue services greater than $\mathrm{y}^{*}$ in the absence of a liability rule). Once substitution effects are introduced, however, this conclusion must be modified. People leaving activity $A$ in response to the imposition of liability in effect impose external diseconomies on those remaining by increasing the likelihood that they will encounter a victim and be called upon to rescue. And as $\Theta$ rises when $\mathrm{n}^{\mathrm{a}}$ declines, the utility in activity A for "strong" altruists will decline as well, and some may switch into activity B. 97 Paradoxically, the class of "strong" altruists might oppose a liability rule because after it is imposed the only remaining members of $\mathrm{n}^{\mathrm{a}}$ may be the "strong" altruists, who will then bear the full burden or costs of the rescue. 98 This point would seem to answer the

97. The utility of a "strong" altruist from activity A after the imposition of liablity equals

$$
U^{a}=g\left(w^{r}-\theta C\left(y_{1}\right)\right)+h\left(w^{v}-\theta\left(1-p^{r}\left(y_{1}\right)\right) L_{0}\right)
$$

where $\mathrm{y}_{1}>\mathrm{y}^{*}$. After the initial substitution of "weak" altruists towards activity $B, \theta$ will increase and $U^{Q}$ will decrease as $g()$ and $h()$ fall.

98. This would also depend on the quantity of rescue inputs that "weak" altruists were providing prior to the liability rule. The greater the quantity they were providing, the greater the burden imposed on the "strong" altruists for a given substitution effect. 
common contention that the law's refusal to impose liability for failure to rescue shows an indifference to moral considerations. On the contrary, imposition of liability would reduce the supply of a moral value, altruism.

One must also consider the effect of liability on the behavior of profit-maximizing firms. If shipowners engaged in the business of transporting goods were made liable for failing to rescue pleasure boats in danger, this would increase the expected costs of shipping and induce substitution towards other business activities or less hazardous sea routes (‥e., where there was less likelihood of encountering a ship in peril). The incentive to substitute would be positively related to the probability of encountering a victim, the magnitude of the rescue costs, the proportion of these costs to total costs, and the elasticity of the industry demand curve. Professional rescue firms, whose entire income depended on compensation for rescue services, would be driven into other activities since there would be no way for them to charge for their rescue services.

This may explain why refusal to salvage a ship does not create a right of action in the ship's owner against the potential salvor under admiralty law. Rescue at sea is normally not a by-product of other activity, but is undertaken primarily by professional salvors. They need no compulsion to engage in their chosen business. Equally clearly, imposition of liability without compensation would greatly reduce the total amount of salvage activity by driving the professional out of the market. In terms of our analysis, the tax effect of liability would presumably be far greater than where the tax is imposed on an activity that yields the actor benefits that are unrelated to his rescue activities. Merely to note that liability will have substitution effects does not answer the question of the net effect of liability on the probability 
of rescue, which depends on both the probability that the victim will be found (as potential rescuers substitute away from hazardous activities) and the probability that, once he is found, he will be rescued (previously defined as $\mathrm{p}^{\mathrm{r}}$ ). To illustrate, assume that the number of victims found $(F)$ is a function of both the number of victims and potential rescuers in $A$, as in

$$
F=F\left(v, n^{a}\right)
$$

where $F$ is assumed to be homogeneous of degree one with positive first and negative second derivatives. The probability that a given victim will be found (which is distinct from $\Theta$, the probability that a given potential rescuer will find or locate a victim) is

$$
\delta=\delta\left(\mathrm{n}^{\mathrm{a}} / \mathrm{v}\right)
$$

which is a positive function of the ratio of $\mathrm{n}^{\mathrm{a}}$ to $\mathrm{v} .99$ Thus, a decline in the number of potential rescuers in response to the liability rule will reduce the probability that a victim is found (holding constant the number of victims). However, a decline in this ratio will raise $\theta$, the prob-

99. We have

$$
\mathrm{F}=\mathrm{F}\left(\mathrm{v}, \mathrm{n}^{\mathrm{a}}\right)
$$

which can be written

$$
\mathrm{F}=\mathrm{v} \delta\left(\mathrm{n}^{\mathrm{a}} / \mathrm{v}\right)
$$

from the assumption of homogeneity of degree one. Since

$$
\begin{aligned}
& \frac{\partial F}{\partial v}=\delta-\frac{n^{a}}{v} \delta^{\prime}>0 \\
& \frac{\partial F}{\partial n^{a}}=\delta^{\prime}>0
\end{aligned}
$$

it follows that $\delta^{\prime}(>0)$ is a positive function of the ratio of $n^{a}$ to $v$. 
ability that a given potential rescuer will find a victim. ${ }^{100}$

Since the unconditional probability of rescue equals $\delta p^{r}$, the net effect of liability is unclear. On the one hand, given that the victim is located, the conditional probability of rescue $\left(p^{r}\right)$ will rise on average since relatively weak altruists ( increase their supply of inputs to $\mathrm{y}^{*}$, whereas those persons supplying more than $\mathrm{y}^{*}$ will continue to supply this quantity. On the other hand, the tax imposed by the liability rule will induce some potential rescuers to substitute away from the hazardous activity, which will tend to reduce the likelihood that the victim is found. We cannot tell a priori which of the two effects will dominate. Should the substitution effect dominate, however, the actual effect of liability will be contrary to its intended effect of increasing the number of rescues.

The relative importance of the offsetting effects on $\delta$ and $\mathrm{p}^{\mathrm{r}}$ has implications for the number of victims (previously assumed constant) in the hazardous activities. If the effect on $\mathrm{p}^{\mathrm{r}}$ dominates and the unconditional probability of rescue rises, victims not only would substitute away

100. $\theta$ is written as

$$
\theta=\left(n^{a} / v\right)^{-1} \cdot \delta
$$

and

$$
\frac{\partial \theta}{\partial\left(n^{a} / v\right)}=-\left(n^{a} / v\right)^{-2}\left(\delta-\frac{n^{a}}{v} \delta^{\prime}\right)<0
$$

from the assumption that $\partial F / \partial v>0$. 
from their own inputs of safety 101 but the number of victims in A would increase as hazardous activities became more attractive. This would generate further adjustments in $\theta$ and further substitutions away from hazardous activities on the part of potential rescuers. On balance, the equilibrium value of the unconditional probability would increase (otherwise additional victims would not have entered in the first place). Alternatively, if the negative effect on $\delta$ dominates, victims would substitute towards their own safety and the supply of victims in the hazardous activity would fall.

Up to now we have limited our analysis of altruism to rescues motivated by the existence of interdependent preferences. Suppose, however, that rescuers are also motivated by a desire to be recognized as altruists and by possible future rewards that result from such recognition, Under a regime of liabiitity for failure to resciue, it would be impossible for a rescuer to prove that he was motivated by altruism--for how could he negate the inference that he really was motivated by fear of liability? This would, in turn, increase the incentive for potential rescuers to substitute away from hazardous activities, thus reducing the unconditional probability of rescue.

A further consideration is the cost of administering a liability rule. Legal-error costs in particular might be high because of the difficulty, in many settings (…g., on a crowded beach), of identifying potential

101. A more complicated liability rule would take account of the victim's inputs of safety, and might impose liability for failing to rescue on condition that the victim provided the optimal quantity of his own safety. This in turn would eliminate the substitution between own safety and the inputs of rescuers. 
rescuers. If as a result only a fraction of those who failed to attempt a rescue were held liable, this would reduce the tax effect of a liability rule and so reduce the substitution away from hazardous activities. But it would equally reduce the incentive to rescue created by liability. And one (adverse) effect of a liability rule--its tendency to reduce the gains from altruistic rescue to those rescuers who desire recognition of their altruism--might not be appreciably weakened by a high degree of error in the administration of the rule. A rescuer would still have a very hard time proving that he had been motivated by altruism rather than by fear of legal sanctions--however weak those sanctions might appear to be in practice because of the amount of error in the system. In sum, in circumstances where the incidence of error is likely to be great, the objections to liability are strengthened.

2. The Legal Position. Although the preceding analysis does not prove that the common law's refusal to impose liability for failure to rescue is efficient, neither can one conclude, as has been argued, that the absence of such a rule is necessarily a sign of inefficiency. Efficiency principles may also explain the growing judicial support for an exception to the nonduty of rescue in cases where the potential rescuer caused, even if nontortiously, the emergency. ${ }^{102}$ By identifying a best-

102. The leading case is Montgomery v. National Convoy \& Trucking Co., 186 S.C. 167, 195 S.E. 247 (1937), discussed in Richard A. Epstein, supra note 3 , at 191-93. For recent cases following Montgomery are Zylka v. Leikvoll, 144 N.W. 2d 358, 367 (Minn. 1966); Scatena v. Pittsburgh \& New England Trucking, 319 N.W. 2d 730 (Mass. 1974). Tr.e "last clear chance" rule represents an earlier instance of this principle. See, for example, Kumkumian v. City of New York, 305 N.Y. 167, 111 N.E. 2d 865 (1953). There are two offsetting factors that bear on the exception to the no-duty principle here. The costs of rescue tend to be uniformly low, increasing the likelihood that altruism alone will be a sufficient inducement to rescue. On the other hand, the tax effect of liability is likely to be insignificant, given the low costs. 
placed rescuer, causation greatly reduces the legal-error costs of imposing Good Samaritan duties.

Tort writers have noted a number of other apparent exceptions to the no-duty-to-rescue doctrine. ${ }^{103}$ The main ones are:

(1) A railroad has a duty to assist a passenger who becomes ill on a train.

(2) A bar cannot allow an obviously drunk customer to wander off at closing time in circumstances where he is likely to get hurt, even though the bar was not at fault in the customer's getting drunk in the first place.

(3) An employer must render assistance to an infured employee at the work site.

(4) If a hospital emergency room customarily treats anyone who seeks admittance to it, it cannot turn away one obviously in need of immediate medical assistance.

But these are not really exceptions to the no-duty doctrine. That doctrine properly has reference to the rescue of strangers rather than to rescues that occur in the course of a contractual relationship. The real analogy to these "exceptions" is the doctrine of agency of necessity discussed earlier. For example, that the railroad should render assistance to an obviously ill and disabled passenger is a reasonably implied term of the contract of carriage. Even the emergency-room example fits this mold. The custom of treating all comers invites prtentially costly reliance on

103. See, for example, William L. Prosser, Law of Torts 340-44 (4th ed. 1971). 
the part of the ill or injured person who requires immediate assistance. 104

European countries (excluding England) generally impose Good Samaritan duties even on mere bystanders. An interesting question is whether the difference can be referred to factors in our analysis that would suggest greater net benefits to a liability rule under conditions prevailing on the Continent. For example, while it is widely asserted that the Continental rule reflects a greater strain of altruism in Continental than in English temperaments, the opposite would be more congruent with the model developed above. 105

The Continental rules appear to contain at least two economizing features. First, liability is not imposed where the cost of the rescue would exceed its value. Second, it is generally confined to cases where the costs of rescue are trivial; this seems calculated to insure that the net social benefits of liability (deducting the costs of operating the legal system) will be positive. A third feature is more questionable: the successful rescuer is entitled to a reward for the rescue. By eliminating (or by reducing) the tax effect of liability, the entitlement to a reward should reduce the number of rescuers substituting away from hazardous activities; but for reasons explored earlier the adminsitrative costs are apt to be

104. A genuine exception to the no-duty-to-rescue doctrine is created by statutes requiring people involved in automobile accidents to render assistance to anyone who may be injured--regardless of causation. Among the factors conceivably justifying such statutes are the ease of identifying persons in a position to rescue and the lack of good substitutes for driving, making it unlikely that the tax effect of liability is great.

105. Another explanation is suggested in William M. Landes \& Richard A. Posner, Altruism in Law and Economics (forthcoming in Am. Econ. Rev., May 1978). 
quite high. Fourth, the reward permitted under Continental law is not equal to the full consumer surplus generated by the rescue. It is generally limited to reimbursement of out-of-pocket expenses. Since this is an inadequate reward to stimulate rescues by nonaltruists, it is understandable that it is coupled with liabillty.

\section{Waiving the Rescuer's Liability}

A distinct approach to the problem of rescue is to relax the liabilities of the rescuer. There are two principal approaches, one statutory and one common law. The statutory approach goes confusingly by the name of "Good Samaritan." The typical Good Samaritan statute excuses the rescuer-normally a physician rendering assistance in an emergency--from liability for ordinary as distinct from gross negligence. Such statutes are puzzling from an economic standpoint. The principal beneficiary is the physician who, as we have seen, is entitled to his ordinary fee when he renders assistance in an emergency (no Good Samaritan, he), a fee that includes his malpractice insurance premium. Perhaps these statutes are to be explained, as so much legislation is to be explained--including other legislation affecting physicians--by the political power of the beneficiaries rather than by the community's interest in promoting efficiency.

The common law approach goes by the name of "incomplete privilege" and is codified in section 122 of the Restatement of Restitution. If, for example, A ties up at $B^{\prime}$ 's dock to avoid being wrecked in a storm, and causes damage to the dock, A has a legal right to use B's dock, given the existence of an emergency which precludes bargaining; but he has to pay for 
any damage caused. 106 There is a close resemblance between this rule and the principle of eminent domain in taking land, except that this application of the eminent-domain principle makes more sense than most conventional applications since here transaction costs preclude a noncoercive exchange. However, at least if administrative costs are ignored, the law would seem mistaken in limiting the dock owner's claim to damage sustained. He should in principle receive the competitive market value of $A^{\prime}$ 's use of his dock (which would include any risk premium to cover possible damage); otherwise there will be insufficient dock building.

Section 122 contains two major exceptions to "incomplete privilege," i.e., two cases where the "rescuee" is not required to compensate the "rescuer." The first is where the danger was created, even if nontortiously, by the owner of the property damaged in effecting the rescue. For example, A is attacked by B's dog in circumstances where B is not liable for the attack (e.g., he had no reason to know of the dog's vicious disposition), and A kills the dog in self-defense. A can do this without having to pay $B$ for the loss of the dog. This reduces the incentives for persons to avoid dogs (especially small ones) but increases the incentives of dog owners to keep their dogs off the street compared to a rule that requires A to pay for $B^{\prime} s$ dog. There is no basis for a presumption that a duty to reimburse would improve resource allocation.

The second exception is where the danger averted by damaging another's property is a public catastrophe rather than a private harm. That is, the rescue confers social benefits that are not fully captured by the person

106. This is the result of the Vincent case, discussed at note 75 supra. 
who creates them, so neither should he be fully liable for the costs. If the catastrophe is truly public, in the sense that a great many people are affected, the cost share property allocable to the person who averts the catastrophe may be so slight as to justify excusing him from all liability.

\section{CONCLUSION}

This paper has developed an economic model designed to predict the conditions under which the law will intervene to encourage rescues and the method of intervention that will be chosen, and has compared the predictions of the model with the actual rules and outcomes of the legal system. We have found impressive congruence, reinforcing our belief that the rules of the judge-made law are best explained as efforts--however unwitting--to bring about efficient results. Our findings are a challenge to the scholars who are unsympathetic to economics even as a method of positive (as distinct from normative) analysis of law--and who, in the areas of law surveyed in this paper, have tended to "explain" legal outcomes by reference to notions of fairness or justice--to develop a positive theory of law more powerful and comprehensive than the economic. 